\title{
Chancen für die Bistumszeitungen
}

\author{
von Rüdiger Schulz
}

Die negative Auflagenentwicklung der Kirchenzeitungen in Deutschland hält noch immer an. Seit 1963, als die Bistumspresse während des Zweiten Vatikanischen Konzils mit 2,4 Millionen Exemplaren ihren Höchststand erreichte, hat sich die Auflage praktisch halbiert (Ende 1994: 1,25 Millionen). Versuche, diesem Trend z.B. durch LayoutVeränderungen, Änderungen der redaktionellen Angebote, durch Verlagskooperationen oder verstärkte Marketingaktivitäten entgegenzuwirken, sind bisher ohne durchschlagenden Erfolg geblieben. Sie haben den Abschmelzungsprozeß möglicherweise abgemildert, aber keineswegs gestoppt: 1995 sank die Verkaufsauflage im Durchschnitt aller Kirchenzeitungen erneut um 3,5\%.1 Dieser anhaltende Auflagenschwund veranlaßte die MEDIEN-DIENSTLEISTUNG GmbH (MDG), München, das INSTITUT FÜR DEMOSKOPIE ALLENSBACH mit der Durchführung einer vergleichenden Situationsanalyse von 18 deutschen Bistumszeitungen zu beauftragen.2 Nach vorbereitenden explorativen Interviews wurde dazu zwischen Juni 1994 und Januar 1995 eine umfassende empirische Bestandsaufnahme in mehreren Untersuchungsschritten durchgeführt, und zwar aus unterschiedlichen Perspektiven. In ausführlichen mündlich-persönlichen Interviews wurden dazu befragt als

- Kommunikatoren

22 Bischöfe als Herausgeber

17 Verleger von Kirchenzeitungen

19 Chefredakteure von Kirchenzeitungen

- Rezipienten

1.871 Abonnenten einer Bistumszeitung

771 Abbesteller (Ex-Abonnenten einer Bistumszeitung)

- Potentielle Multiplikatoren

137 Priester

179 Vertreter katholischer Laiengremien

- Potentielle Abonnenten

486 Katholiken im Rahmen einer bundesweiten repräsentativen Bevölkerungsumfrage.

Dr. rer. pol. Rüdiger Schulz ist leitender wissenschaftlicher Mitarbeiter im Institut für Demoskopie, Allensbach.

1 L.t. Auflagenstatistik der MDG vom 18. Januar 1996.

2 An der Untersuchung beteiligten sich die Kirchenzeitungen der Erzbistümer Freiburg, München und Freising sowie Paderborn und der Bistümer Aachen, Berlin, Eichstätt, Essen, Fulda, Hildesheim, Limburg, Mainz, Osnabrück, Passau, Regensburg, Rottenburg-Stuttgart, Speyer und Trier sowie der Tag des Herrn, Bistumszeitung für die Bistümer Dresden-Meißen, ErfurtMeiningen, Magdeburg und Schwerin. 
Ergänzend wurden 18 Vertriebs- bzw. Werbeleiter von Kirchenzeitungen schriftlich befragt.

Zeitgleich wurde parallel am Institut für Publizistik der Johannes Gutenberg-Universität Mainz (Prof. Hans Mathias Kepplinger) eine vergleichende Inhaltsanalyse der 18 einbezogenen Bistumszeitungen vorgenommen.

Ziel dieser Untersuchungen war es, aus den Befragungsergebnissen Entscheidungshilfen für eine konzeptionelle Neuorientierung der Bistumspresse abzuleiten, die angesichts des andauernden Leserschwundes dringend geboten scheint. Die Ergebnisse dieser Untersuchung wurden den beteiligten Verlagen in fünf Berichten vorgelegt ${ }^{3}$ sowie in 14 bistumsbezogenen Einzeldarstellungen, die das spezifische Profil des jeweiligen Bistumsblattes durch Vergleiche mit dem Gesamtdurchschnitt aller Bistumszeitungen herausstellten.

Im hier vorgelegten Überblicksbericht über die wichtigsten Erkenntnisse werden die Kernbefunde dieser Untersuchung einer breiteren Öffentlichkeit zugänglich gemacht. Ferner soll hier die Frage beantwortet werden, welche neuen Erkenntnisse - über die Befunde der drei wichtigsten Vorgängerstudien, die unter der Bezeichnung ,Feldbefragung' bekannt gewordene Studie von 19754, die "Resonanzanalyse' von $1985^{5}$ und die ,Funktionsanalyse Bistumsblätter' von $1986^{6}$ hinaus die aktuelle Situationsanalyse "Chancen für die Bistumszeitungen' erbracht hat.

$3 \quad$ MDG/IfD Allensbach: CHANCEN FÜR DIE BISTUMSZEITUNGEN 1994;

Band I: Situationsanalyse, Empfehlungen

Band II: Themenstruktur, Sprache und Gestaltung

Band III: Form und Inhalt der Bistumszeitungen

Band IV: Dokumentation

Band V: Werbung

4 Institut für Kommunikationsforschung e.V. (IfK): FELDBEFRAGUNG Kommunikations- und Informationserwartungen der katholischen Bevölkerung gegenüber kirchlichen Massenmedien - insbesondere der Kirchenpresse. Teil D. Interpretationen, Wuppertal, 1975.

5 Media Markt Analysen (MMA): Kirchenzeitungen im Spiegel ihrer Leser. Ein Kommentar zu sechs Resonanzanalysen. Frankfurt am Main, 1986.

6 Media Markt Analysen (MMA): Funktionsanalyse Bistumsblätter. Analytische Zusammenfassung und Bewertung der Ergebnisse. München, 1987. 


\section{Zur Lage der Kirchenzeitungen heute}

Die katholischen KONPRESS-Titel7, das sind im wesentlichen die Bistumszeitungen, erreichen auch heute noch 23\% aller Katholiken ab 14 Jahre im weitesten Leserkreis, das sind rund 4,9 Millionen Katholiken. Darunter zählen $10,7 \%$ bzw. 2,3 Millionen zu den regelmäßigen, 12,0\% bzw. 2,6 Millionen zu den sporadischen Lesern.

Die ungünstige Altersstruktur des Publikums der Kirchenzeitungen, die Michael Schmolke schon in seinem Kommentar zur Feldbefragung von 1975 beklagte ("Die Leserschaft ist tatsächlich alt") ${ }^{8}$, ist in den 20 Jahren seither noch ungünstiger geworden: Waren 1975 erst 39\% der Abonnenten 60 Jahre oder älter, so ist der Anteil in diesem höchsten Alterssegment inzwischen auf $56 \%$ gestiegen. Wurden in der Feldbefragung von 1975 immerhin noch $20 \%$ unter-40jährige Kirchenzeitungsabonnenten ermittelt, sank deren Anteil zwischenzeitlich auf jetzt nur noch 8\%.9 (Zum Vergleich: der bevölkerungsrepräsentative Anteil dieses jüngeren Alterssegments unter den Katholiken beträgt 34\%.) Damit ist die Überalterung des Abonnentenkreises der Kirchenzeitungen weiter fortgeschritten (Tabelle 1).

Hinzu kommt jetzt ein deutliches Übergewicht weiblicher Abonnenten (Frauen: $64 \%$, Männer: $36 \%$ ).

Die Situationsanalyse von 1994 hat auch Schmolkes Aussage bestätigt, daß „Kirchenpresse, speziell Bistumspresse vorwiegend kircheninterne Kommunikation ist. Sie erreicht hauptsächlich Kirchgänger $^{\prime \prime}{ }^{10}$ Wie schon 1975 werden auch heute mit der Bistumszeitung ganz überwiegend regelmäßige Gottesdienstbesucher erreicht (1975: 83\%, 1994: 79\%).

7 Im Rahmen der Allensbacher Werbeträger-Analysen (AWA) wird seit Jahren kontinuierlich auf breiter statistischer Basis auch die Reichweite der katholischen KONPRESS-Titel ermittelt, das sind im wesentlichen die 24 deutschen Bistumszeitungen. Hinzu kommen das Liboriusblatt, die Deutsche Tagespost, Die christliche Familie sowie die Bildpost mit vergleichsweise geringerer Auflage. Zu den Lesern pro Nummer (LpN) zählen alle, die ein Heft des jeweiligen Titels im Erscheinungsintervall, das ist bei Bistumszeitungen in den letzten 7 Tagen, gelesen oder durchgeblättert haben. Zum weitesten Leserkreis (WLK) zählen auch die gelegentlichen Leser.

8 Schmolke, Michael: Kommentar zu wichtigen Ergebnissen der Feldbefragung. In: IfK.(1975), a.a.O., Seite 4.

9 Jüngere Katholiken haben die Bistumszeitungen nur selten selbst abonniert, werden von der Bistumszeitung aber etwas häufiger zumindest als gelegentliche (Mit-)Leser erreicht. So zählen zwar deutlich unterdurchschnittlich viele, aber immerhin noch 13\% der 14-19jährigen Katholiken, $12 \%$ der 20-29jährigen und 18\% der 30-39jährigen zum weitesten Leserkreis.

10 Schmolke, Michael: Kommentar zu wichtigen Ergebnissen der Feldbefragung. In: IfK (1975), a.a.O., Seite 4. 
Soziodemographische Strukturen: Die Uberalterung der Kirchenzeitungen ist weiter Eortgeschritten. Deutliches úbergewicht von Frauen
Tabelle 1

Bundesrepublik Deutschland

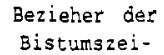

tungen

Feldbefragung 1975

8

\section{Geschieche}

Männer...................4 43

Frauen $\ldots \ldots \ldots \ldots \ldots \ldots \ldots \ldots$

$\overline{100}$
Abonnenten zum Vergleich: einer Kirchen- Katholiken ab zeitung. 16 Jahre

Situations- insgesant aralyse $\quad 1995$

1994

of

\section{is}

\begin{tabular}{lr}
36 & 46 \\
64 & 54 \\
\hline 100 & 100
\end{tabular}

\section{Alterscrupoen}

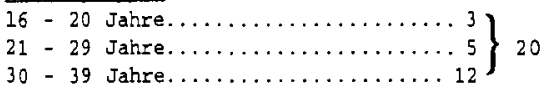

40 - 49 Jahre................. 21

50 - 59 Jahre.................. 20

60 - 69 Jahre............... 25

70 Jahre und älter.

$\overline{100}$

Schulbildung

Hauptschule.................67

Mittlere Reife.............. 19

Abitur..................... 7$\}_{7}$

Abgeschlossenes seudium.......... $\} 14$

$\overline{100}$ $\left.\begin{array}{l}1 \\ 1 \\ 6\end{array}\right\} 8$

13

23

$25\}$

$31\} 56$

$\overline{100}$

60

22

5
13 18

$\overline{100}$

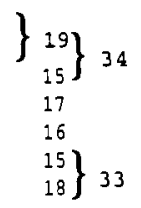

$\overline{100}$

60

25

8) 15

$\overline{100}$

Es gehen in die Kirche, zur Heiligen

Messe, zum Gottesdienst -

jeden sonntag...............63

fast jeden Sonntag............. 20 8 83

ab und $2 u \ldots \ldots \ldots \ldots \ldots \ldots \ldots \ldots$

selten...................

nie.....................

Keine konrete Angabe............

\begin{tabular}{cc}
$\left.\begin{array}{c}56 \\
23\end{array}\right\} 79$ & $\begin{array}{l}15 \\
13\end{array}$ \\
6 & 183 \\
2 & 22 \\
$x$ & 33 \\
100 & 12 \\
\hline
\end{tabular}

$\mathrm{n}=$

1871

496

$x=$ weniger als 0,5 Prozent

QUELLE: Feldbefragung (1975) sowie IfD-Unfragen 1467 und 6010 
Die Parallelität der Entwicklung von kirchlicher Bindung sowie Reichweiten- und Auflagenentwicklung der konfessionellen Presse ist unverkennbar.

Zwischen 1980 und 1994 sank der Anteil der regelmäßigen Gottesdienstbesucher unter den Katholiken ab 14 Jahre von 38 auf 28\%, das sind relativ gesehen $26 \%$ (Indexwert: 74 ).

Der Anteil der regelmäßigen KONPRESS-Leser ging im selben Zeitraum um relativ 30\% zurück (Indexwert: 70), die Auflage sank zwischen 1980 und 1994 ebenfalls um 30\% (Indexwert: 70). Dagegen ist der weiteste Leserkreis einschließlich der nur sporadischen Leser vergleichsweise schwächer geschrumpft, und zwar von 27 auf $23 \%$ (Indexwert: 84). Das bedeutet, daß zumindest ein Teil der früher regelmäßigen Leser sich nicht völlig abwandte, vielmehr zumindest noch gelegentlich von KONPRESS-Titeln erreicht wird:

Entwicklung $1980-1994$

$19801994 \quad$ Index

$(1980=100)$

Reichweiten:

Regelmäßige KONPRESS-Leser (LpN)

Weitester Leserkreis (einschließ1.

der nur sporadischen Leser, WLK)

Verkaufsauflage der

Bistumszeitungen

$\begin{array}{rr}15,2 & 10,7 \\ 27,1 & 22,7 \\ & \\ 1,785 & 1,249 \\ \text { Mio. } & \text { Mio. }\end{array}$

Zum Vergleich:

Regelmäßige Gottesdienstbesucher ${ }^{11}$

$38 \% \quad 28 \%$

Angesichts des Gleichschritts dieser Entwicklung drängt sich die Frage auf, ob die Kirchenzeitungen lediglich Opfer einer Abnahme kirchlicher Bindungen sind, unabhängig von der Qualität der redaktionellen Angebote zwangsläufig an Auflage verlieren müssen, wenn sich mehr und mehr Menschen von der Kirche abwenden. Jeder zweite Chefredakteur einer Kirchenzeitung teilt diese Auffassung, während die Bischöfe als Herausgeber und die Verleger mehrheitlich einer differenzierteren Ansicht zustimmen: „Natürlich trägt auch die zunehmende Säkularisierung der Gesellschaft dazu bei, daß kirchliche Zeitungen heute weniger gefragt sind. Aber man darf auch nicht die Augen vor den Schwächen der Kirchenzeitung verschließen. Wenn die Zeitung besser wird und sich stärker an den Leserbedürfnissen orientiert, wird sich das auch

$11 \quad$ Es gehen jeden, fast jeden Sonntag zur Kirche

Basis: Katholiken ab 14 Jahre in den alten Bundesländern 
positiv auf die Auflagenentwicklung auswirken" (Bischöfe: 59\%, Verleger: $53 \%$, Chefredakteure: $37 \%$ ).

Vier Ergebnisse der vergleichenden Situationsanalyse stützen die These, daß die Kirchenzeitungen nicht lediglich Opfer externer, von ihr nicht beeinflußbarer Entwicklungen sind, vielmehr auch eigene, gleichsam ,hausgemachte' Schwächen der Kirchenzeitungen vorliegen.

1. Längst nicht alle kirchennah gebliebenen Katholiken, die jeden, fast jeden Sonntag in die Kirche gehen (28\%), sind regelmäßige Leser der Kirchenzeitung (11\%). Nur gut jeder dritte treue Kirchgänger ist regelmäßiger Leser eines Bistumsblattes (Indexwert 39). Überdurchschnittliche Defizite sind vor allem bei den Unter-30jährigen zu finden, das gilt für junge Unverheiratete und junge Familien gleichermaßen (Schaubild A).

2. Mit den Säkularisierungstendenzen der Gesellschaft allein sind die Abo-Kündigungen nicht zu erklären. Das Gros der befragten Abbesteller hat sich keineswegs ganz von der Kirche entfernt.

Sie gehen weiterhin in überdurchschnittlichem Anteil regelmäßig zur Kirche (56\%, Abonnenten: 79\%, Katholiken insgesamt: 28\%).

Auf einer Skala von 10 (,stark mit der Kirche verbunden') bis 0 (,gar keine Bindung') stufen Abbesteller ihre Verbundenheit mit der Kirche im Durchschnitt bei 7,0 ein, das ist etwas weniger als der Abonnentendurchschnitt $(8,2)$, aber deutlich höher als der Durchschnitt aller Katholiken $(5,2)$.

$58 \%$ der Abbesteller bezeichnen sich als, Gläubiges Mitglied meiner Kirche, stehe $\mathrm{zu}$ ihrer Lehre' (Abonnenten: 81\%, Katholiken insgesamt: $36 \%$ ).

3. Auch viele Priester und Vertreter katholischer Laiengremien kritisieren Inhalt und Form der Kirchenzeitungen. Viele von ihnen sind nicht der Meinung, daß jeder Katholik, dem die Kirche etwas bedeutet, die Bistumszeitung lesen sollte.

Der Aussage "Die Bistumszeitung bringt so viele wichtige kirchliche Informationen und setzt sich mit vielen interessanten und bedeutsamen Themen auseinander, daß eigentlich jeder Katholik, dem die Kirche etwas bedeutet, diese Zeitung lesen sollte"

stimmen zu Priester
$\%$

stimmen nicht zu

Laienvertreter $\%$

48

41

4. Über den Kreis der bisher gewonnenen Leser hinaus gibt es unter Katholiken ein großes psychologisches Interessentenpotential für eine kirchliche oder christliche Zeitschrift (31\%), das sich für Beiträge wie z.B. Nachrichten aus der Kirche, Kommentare zu aktuellen Ereignissen aus kirchlicher Sicht bis hin zu Fragen nach dem Sinn des Lebens, Auseinandersetzung mit wichtigen Werten unserer Gesell- 
schaft und praktische Lebenshilfe wie Ratschläge für Ehe, Familie und Kindererziehung interessiert (Schaubild A).

All dies sind klare Anzeichen dafür, daß die bisherigen Angebote der Kirchenzeitungen nicht attraktiv genug sind, um das große Leserpotential vom Nutzen eines Abonnements zu überzeugen. Das insgesamt durchaus positive Urteil über die Bistumszeitungen resultiert fast ausschließlich aus sehr positiven Urteilswerten der meist älteren Kernleser, deren Erwartungen sie offensichtlich gut erfüllen, während sowohl die wenigen jüngeren Abonnenten, die gewonnen werden konnten, als auch die Abbesteller, Priester und Vertreter katholischer Laiengremien sich deutlich kritischer über die Themenauswahl, Kommentare, aber auch über Fotos, Bilder, die ganze äußere Aufmachung, Gestaltung äußern.

Auf einer Skala von +5 (,ganz ausgezeichnet“) bis -5 ("gefällt überhaupt nicht") bewerten die Abonnenten insgesamt ihre Bistumszeitung im Durchschnitt mit $+3,2$, ältere Abonnenten mit $+3,6$, also sehr positiv, unter-40jährige Abonnenten nur mit $+1,6$, also nur gemäßigt positiv. Auch die befragten Priester und Vertreter katholischer Laiengremien äußern sich sehr viel zurückhaltender (Tabelle 2).

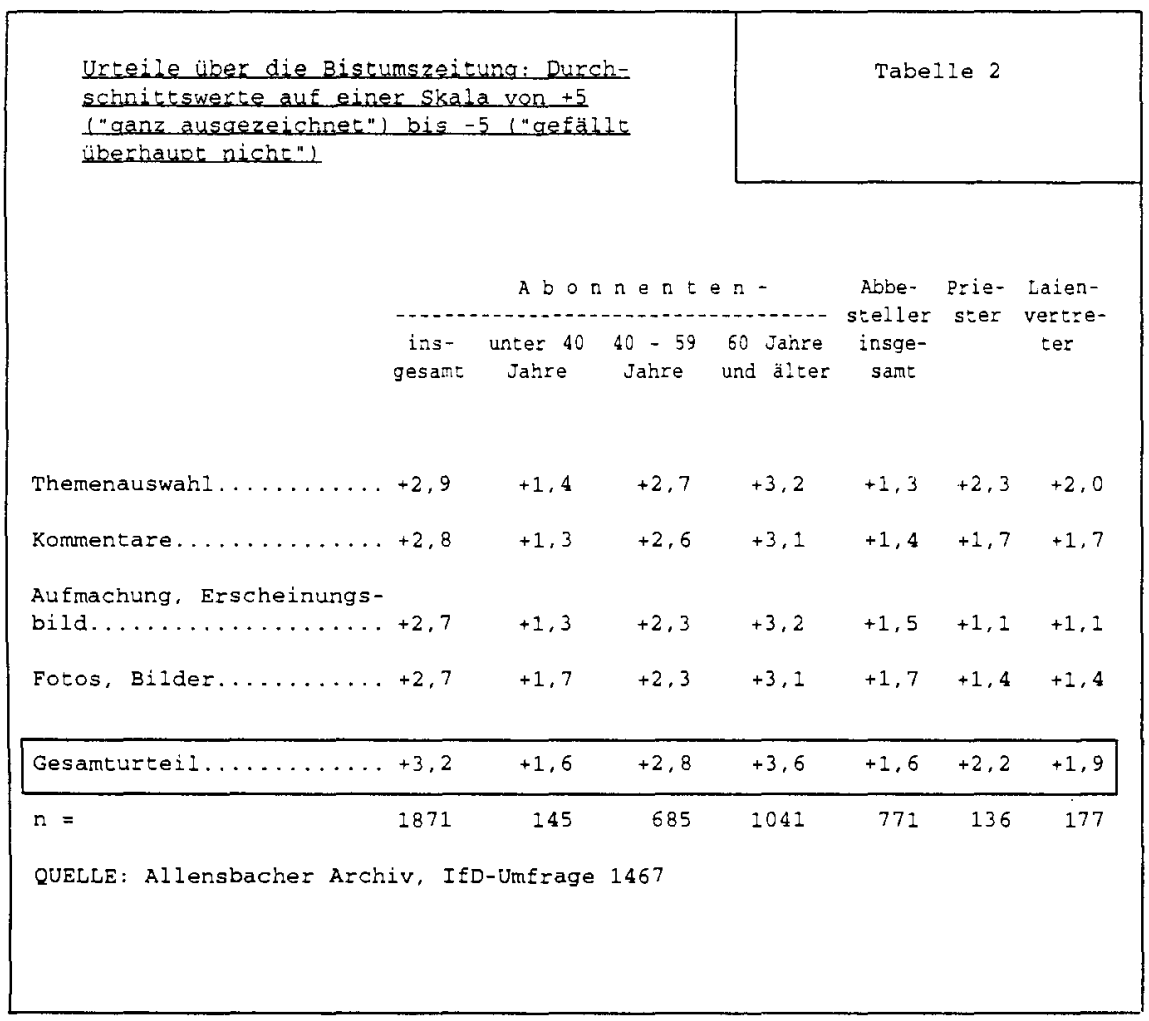




\section{UNAUSGESCHÖPFTE POTENTIALE}

Vergleich der Anteile regelmäßiger Gottesdienstbesucher und regelmäßiger KONPRESS-Leser

- Katholiken, die jeden, last jeden Sonntag in die Kirche gehen Regelmäßige KONPRESS-Leser (LpN)

Katholiken ab 14 Jahre

$28 \%$

Männer 8 8

- 24

Frauen 13

- 32

ALTERSGRUPPEN

14 - 19 Jahre 5

20 - 29 Jahre 4

- 14

30 - 39 Jahre 6

- 16

40 - 49 Jahre $8 y$

23

50 - 59 Jahre $[12$

30

60- 69 Jahre

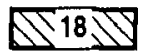

43

70 Jahre und älter

23

\section{LEBENSPHASEN}

$\begin{gathered}\text { Junge Unverheiratete } \\ \text { Junge verheiratete Paare } \\ \text { ohne Kinder } \\ \text { Junge Familien }\end{gathered}$
Familien mit nur älteren
Kindern
Erwachsenen-Haushalte
Ältere Unverheiratete




\section{UNAUSGESCHÖPFTE POTENTIALE}

Vergleich der Anteile regelmäßiger Gottesdienstbesucher und regelmäßiger KONPRESS-Leser

- Katholiken, die jeden, fast jeden Sonntag in die Kirche gehen

Regelmäßige KONPRESS-Leser (LpN)

Index: (Regelmäßige

Kirchen-

SCHULABSCHLUSS

Hauptschule ohne Lehre $\triangle 15 \checkmark$

Hauptschule mit Lehre 113

Mittlere Reife $[9]$

Abitur, Studium [9]

BERUFSKREISE

Selbständige, freiberuflich

Tätige

Landwirte

$\$ 12$

28

$38 \%$

- 27 besucher $=100$ )

Leitende Angesteilte,
Beamte Beamte 10.

Nichtleitende Angestelite, Beamte

Facharbeiter [11]

27

- 26

Sonstige Arbeiter

ORTSGRÖSSEN

Unter 5000 Einwohner $10 \mathrm{~J}$

5000 - 20.000 Einwohner

20.000 - 100.000 Einwohner

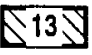

- 31

100.000 Einwohner u.mehr [8]

- 28 
Obwohl die hier nachgewiesene Parallelität von Auflagen- bzw. Reichweitenverlusten und Abnahme kirchlicher Bindungen auffällig ist, kann die Säkularisierung der Gesellschaft allein die bedrohte Situation der Kirchenzeitungen nicht voll erklären. Einerseits reicht das Interesse der Katholiken an Themen wie "Kirche und Glauben' weit über den Kreis der bisher gewonnenen Leser hinaus, andererseits engagieren sich auch Priester und Mitglieder von katholischen Laiengremien vor Ort, in den Kirchengemeinden nur unzureichend für die Bistumszeitung, und auch kirchentreue Katholiken wenden sich von der Bistumszeitung ab.

Abbesteller vermissen in der Kirchenzeitung vor allem ,ausgewogene, nicht einseitige Berichterstattung', ,nützliche Informationen", auch "Mut zu umstrittenen Themen' sowie ,Meinungen, die von der offiziellen Linie der Kirche abweichen'. Offensichtlich wünschen sie sich die Bistumszeitung weniger als ,Sprachrohr der Amtskirche, des Bichofs', vielmehr als Forum, das unterschiedlichen Meinungen Raum gibt. So wird konkrete Kritik an den Angeboten der Kirchenzeitung vor allem von jenen geäußert, die in der Bistumszeitung nicht wie die große Mehrheit der zufriedenen Abonnenten Bestärkung im tradierten Glauben, Stellungnahmen von Papst und Bischof sowie Nachrichten aus dem kirchlichen Leben, auch aus dem Bistum suchen, sondern eine stärkere Öffnung der Kirchenzeitung als Meinungsforum für die Vielfalt kirchlicher Positionen fordern.

Etwa jeder dritte befragte Abbesteller hat sich nicht ganz von der Bistumszeitung abgewandt, liest die Bistumszeitung regelmäßig oder sporadisch weiter, wobei er die Bistumszeitung jetzt bei anderen (z.B. Freunden, Bekannten, Nachbarn) mitliest oder sie ohnehin allgemein zugänglich vorfindet, z.B. im Gemeindehaus, im Alters- oder Pflegeheim. Immerhin jeder vierte Abbesteller $(26 \%)$ könnte sich vorstellen, die Kirchenzeitung später wieder einmal zu abonnieren.

$\mathrm{Da}$ die kirchlichen und religiösen Bindungen schwächer werden, dürfte - wie auch die geringe Identifikation mit dem Bistum - die Neuakquisition stärker behindern, als dies die Abwanderung einmal gewonnener Abonnenten erklärt. Die Abwanderungsursachen reichen von ,hohem Lebensalter' über ,zu starke finanzielle Belastung' (vor allem, aber nicht nur in den neuen Bundesländern), konkreter Kritik an Form und Inhalt bis hin zu wenigen von vornherein nur aus Gefälligkeit gewonnenen, an den Inhalten der Bistumszeitung nicht wirklich interessierten Abonnenten.

\section{Aussagen zur Nutzung der Bistumszeitungen}

Die Situationsanalyse enthält eine Fülle von Erkenntnissen über die Nutzung der bisherigen Angebote, auch was man in der Bistumszeitung vermißt. Die Beiträge in der Bistumszeitung werden insgesamt gut genutzt: 33\% der Abonnenten lesen alle, fast alle Seiten, jeweils 25\% 
,etwa drei Viertel' bzw. ,etwa die Hälfte', also insgesamt $83 \%$,etwa die Hälfte oder mehr'. Von den wenigen unter-40jährigen Lesern lesen nur $12 \%$ alle, fast alle Seiten, weitere $20 \%$ etwa drei Viertel, jeder dritte allerdings nur etwa ein Viertel oder weniger.

Frage: „Wieviel lesen Sie im Durchschnitt ...?

\begin{tabular}{lrrrrr} 
& \multicolumn{7}{c}{ Abonnenten } \\
& insge- & unter 40 & $40-49$ & $50-59$ & 60 Jahre \\
& samt & Jahre & Jahre & Jahre & u. älter \\
Alle, fast alle Seiten & $\%$ & $\%$ & $\%$ & $\%$ & $\%$ \\
Etwa drei Viertel & 33 & 12 & 21 & 25 & 41 \\
Etwa die Hälfte & 25 & 20 & 25 & 30 & 24 \\
Etwa ein Viertel & 25 & 36 & 35 & 25 & 22 \\
Nur ganz wenige & 10 & 13 & 12 & 12 & 8 \\
Keine Angabe & 6 & 19 & 7 & 7 & 4 \\
& 1 & $x$ & $x$ & 1 & 1 \\
& 100 & 100 & 100 & 100 & 100
\end{tabular}

Die durchschnittliche Lesedauer pro Ausgabe ist mit 68 Minuten hoch, sie schwankt allerdings zwischen 40 Minuten bei den Unter-40jährigen und 81 Minuten bei den 60jährigen und älteren. Der Anteil der Abonnenten, die vieles in der Bistumszeitung interessiert, ist mit $81 \%$ sehr hoch, wenn auch bei den jüngeren deutlich schwächer (Tabelle 3). Der Anteil derjenigen, die die Kirchenzeitung lediglich aus Sympathie oder Tradition lesen, ist offensichtlich geringer als erwartet.

Auch die Themenauswahl wurde auf einer Stapelskala von +5 (, ausgezeichnet“) bis -5 (,gefällt überhaupt nicht“) mit im Durchschnitt $+2,9$ gut bewertet, von den jüngeren Abonnenten allerdings deutlich schlechter $(+1,9)$ als von den älteren $(+3,1)$.

Von den Abonnenten werden am stärksten beachtet (,immer, fast immer gelesen"):

- ,Berichte aus meiner Kirchengemeinde“ (64\%);

- Stellungnahmen der Kirche zu sozialen, gesellschaftspolitischen Fragen unserer Zeit' (52\%);

- Stellungnahmen, Aussagen des Papstes' (49\%) und

- Stellungnahmen, Aussagen des Bischofs' (49\%) sowie

- ,Leserbriefe' (48\%);

- 'Aus der Kirchengeschichte, Geschichte der Diözese, Pfarrei' (48\%);

- Stellungnahmen der Kirche zu politischen Fragen unserer Zeit (z.B. zum Krieg in Bosnien, zum Konflikt zwischen Israelis und Arabern, zur Moral in der Politik' (48\%);

- ,Personalien aus der Kirche (z.B. Ernennungen, Ehrungen, Jubiläen, Todesfälle)' $(48 \%)$; 
FRAGE: "Die Einstellung der Leser zu ... kann ja ganz unterschiedlich sein. Da gibt es die Leser, die diese zeitung lesen, weil sie vieles darin interessiert, und es gibt diejenigen, die ... zwar abonniert haben, aber sich nicht so sehr für diese zeitung interessieren. Wozu würden Sie sich eher zählen, zu denjenigen, die vieles in ... interessiert, oder eher zu denjenigen, die sich nicht so sehr dafür interessieren?"

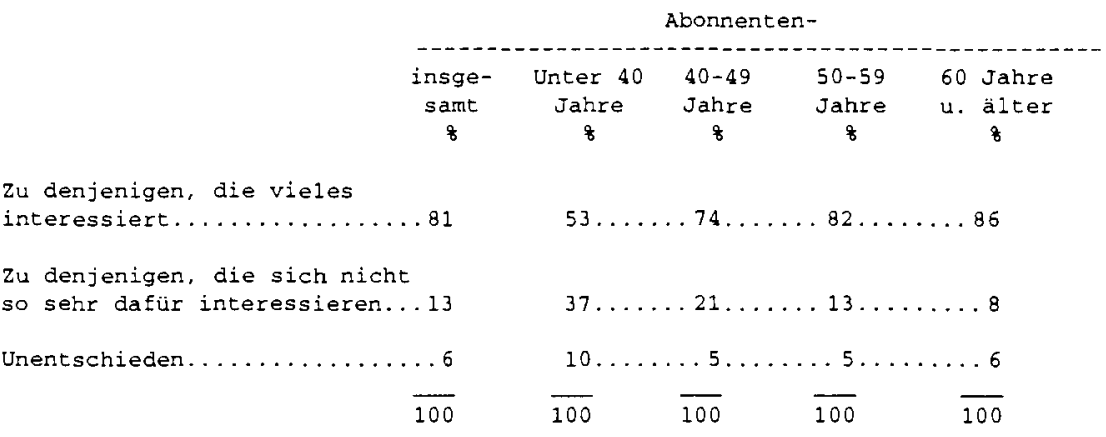

QUELLE: Allensbacher Archiv, IfD-Umfrage 1467

- ,Glaubensverkündigung, christliche Botschaft' $(48 \%)$;

- Stellungnahmen der deutschen Bischöfe, der Bischofskonferenz' (47\%);

- ,Berichte aus dem Leben des Bistums' (46\%).

Wenig genutzt werden vor allem Buchbesprechungen (17\%), Jugendseite (17\%), Kinderseite (16\%) sowie Geschäftsanzeigen (12\%).

Trotz dieser Informationsfülle werden in beachtlichem Anteil von den Abonnenten zusätzliche oder häufiger Beiträge gewünscht, vor allem

- Wie junge Leute wieder für die Kirche begeistert werden können $(58 \%)$;

- Artikel, die deutlich machen, wie wichtig der Glauben in unserer Zeit ist $(48 \%)$;

- Was die Kirche zur Versöhnung beitragen kann (44\%);

- Glaubenszeugnisse (,Berichte über Leute, die ihren Glauben leben und bekennen', 30\%);

aber durchaus auch in der Kirche umstrittene Themen, wie

- zu Ämtern für Frauen in der Kirche (32\%), oder

- über die Auseinandersetzungen um den Zölibat (36\%);

- wie die Kirche mit Geschiedenen umgeht (38\%) bis hin zu

- Kritik an den Äußerungen des Papstes (24\%). 
Auch die ebenfalls dazu befragten Bischöfe, Chefredakteure und Verleger sehen wichtige Themen noch nicht ausreichend in der Bistumszeitung berücksichtigt. Insbesondere zusätzliche Glaubenshilfen, Glaubenszeugnisse werden empfohlen, aber auch verstärkter Auseinandersetzung mit umstrittenen Themen wollen die Kommunikatoren nicht ausweichen, allenfalls sehen sie Themen wie Zölibat oder die Auseinandersetzung mit Kirchenkritikern, wie z.B. Küng oder Drewermann, bereits ausreichend in den Kirchenzeitungen behandelt.

\section{Das ,psychologische Potential' für eine kirchliche oder christliche Zeitung, Zeitschrift}

Um das weiteste Potential für eine christliche oder kirchliche Zeitung, Zeitschrift auszuloten, wurde im Januar 1995 im Rahmen einer für die Bevölkerung ab 16 Jahre in den alten und neuen Bundesländern repräsentativen Umfrage ein solches Medienangebot, das der Prototyp einer Kirchenzeitung sein könnte, wie folgt auf einer Liste vorgestellt:

Diese christliche oder kirchliche Zeitschrift enthält

- Nachrichten aus der Kirche, den Gemeinden und Bistümern;

- Kommentare zu aktuellen Ereignissen aus kirchlicher Sicht;

- Berichte über kirchliche Ereignisse und Entwicklungen in aller Welt;

- Auseinandersetzung mit Sinnfragen, mit Fragen nach dem Sinn des Lebens;

- Auseinandersetzung mit wichtigen Werten in unserer Gesellschaft;

- Ratschläge für Ehe, Familie und Kindererziehung.

Der Kreis, der nach eigener Aussage bereits eine christliche oder kirchliche Zeitung, Zeitschrift des hier skizzierten ,Prototyps' liest, umfaßt $16 \%$, das Interessentenpotential weitere $31 \%$ aller Katholiken ab 16 Jahre. Demnach spricht dieser ,Prototyp' einer kirchlichen oder christlichen Zeitung, Zeitschrift insgesamt $47 \%$ der Katholiken an, das sind weit mehr als die bisher von katholischen Printmedien Erreichten $(34 \%) .12$

Dieser Befund ist um so bemerkenswerter, als unter den inhaltlichen Angeboten einer solchen Zeitung, Zeitschrift nicht etwa nur vage von Beiträgen wie ,Auseinandersetzung mit Sinnfragen' bzw. ,mit wichtigen Werten in unserer Gesellschaft ${ }^{\prime}$ die Rede war, vielmehr wurden ganz bewußt auch spezifisch kirchliche Angebote aufgeführt, wie z.B. "Nachrichten aus der Kirche', „Berichte über kirchliche

$1234 \%$ der im Januar 1995 bevölkerungsrepräsentativ befragten Katholiken geben an, daß sie bereits eine Zeitung oder Zeitschrift mit christlichen oder kirchlichen Themen lesen (weitester Leserkreis einschließlich der sporadischen Leser). 
Ereignisse und Entwicklungen in der Welt' oder ,Kommentare aus kirchlicher Sicht'.

In Schaubild B ist dieses, psychologische Interessentenpotential' ${ }^{\prime} \mathbf{3}$ nach soziodemographischen und religionssoziologischen Merkmalen untergliedert. Auffällig ist, daß das zusätzliche Potential nicht nur unter kirchennahen Katholiken, die jeden, fast jeden Sonntag in die Kirche gehen, stark ist $(48 \%)$, sondern auch bei kirchenfernen Katholiken (22\%), nicht nur bei kirchentreuen Gläubigen (47\%), sondern auch bei Katholiken, die von sich sagen "Ich fühle mich als Christ, aber die Kirche bedeutet mir nicht viel" (26\%) bzw. "Ich habe meine eigenen Glaubensansichten ganz unabhängig von der Kirche" (18\%). Wer sich allerdings weder für die Kirche noch für Glaubensfragen interessiert, bekennt freimütig, so eine Zeitung, Zeitschrift „interessiert mich nicht ${ }^{\text {“ }}$ $(92 \%)$.

Ein solches Angebot interessiert selbst die bisher nur schwach erreichten jüngeren Altersgruppen noch in beachtlichem Umfang. So lesen bisher nur 5\% der unter-30jährigen Katholiken zumindest sporadisch eine Zeitung oder Zeitschrift des hier skizzierten ,Prototyps', aber $21 \%$ zählen zum ,psychologischen Potential' dafür (Schaubild B).

Das trotz nachlassender Kirchenbindung breite Interessentenpotential für eine kirchliche oder christliche Zeitschrift erklärt sich aus starkem thematischen Interesse. So interessieren sich Katholiken in beachtlichem Anteil für Themen wie z.B.

- Welche Bedeutung die Kirche in unserer Gesellschaft hat' (36\%);

- Was Glauben in unserer heutigen Zeit bedeutet' (33\%);

- Berichte über kirchliche Ereignisse und Entwicklungen aus aller Welt' (28\%);

- Stellungnahmen und Aussagen des Papstes und der Bischöfe' (28\%);

- Wie man Kindern den Glauben nahebringen kann' (27\%).

Besonders ausgeprägt ist das Interesse an Orientierungshilfe im weitesten Sinne, wie z.B.

- Stellungnahmen, Kommentare zu den Problemen unserer Zeit' $(53 \%)$;

- Über den Sinn des Lebens' (50\%) bis hin zur

- ,Lebenshilfe, wie man im Leben besser zurechtkommt' (39\%).

13 Der Terminus ,psychologisches Interessentenpotential' wurde bewußt gewählt, um zum Ausdruck zu bringen, daß es hier zunächst um psychologiscle Affinität zum angesprochenen Themenkreis einer christlichen oder kirchlichen Zeitung, Zeitschrift geht. Inwieweit dieses Interessentenpotential als Leser oder gar Abonnenten erschlossen werden kann, hängt u.a. ab von den konkreten Inhalten, Gestaltung, Preis usw. 


\section{Bereits gewonnene Leser und psychologisches Potential für kirchliche oder christliche Zeitungen, Zeitschriften}
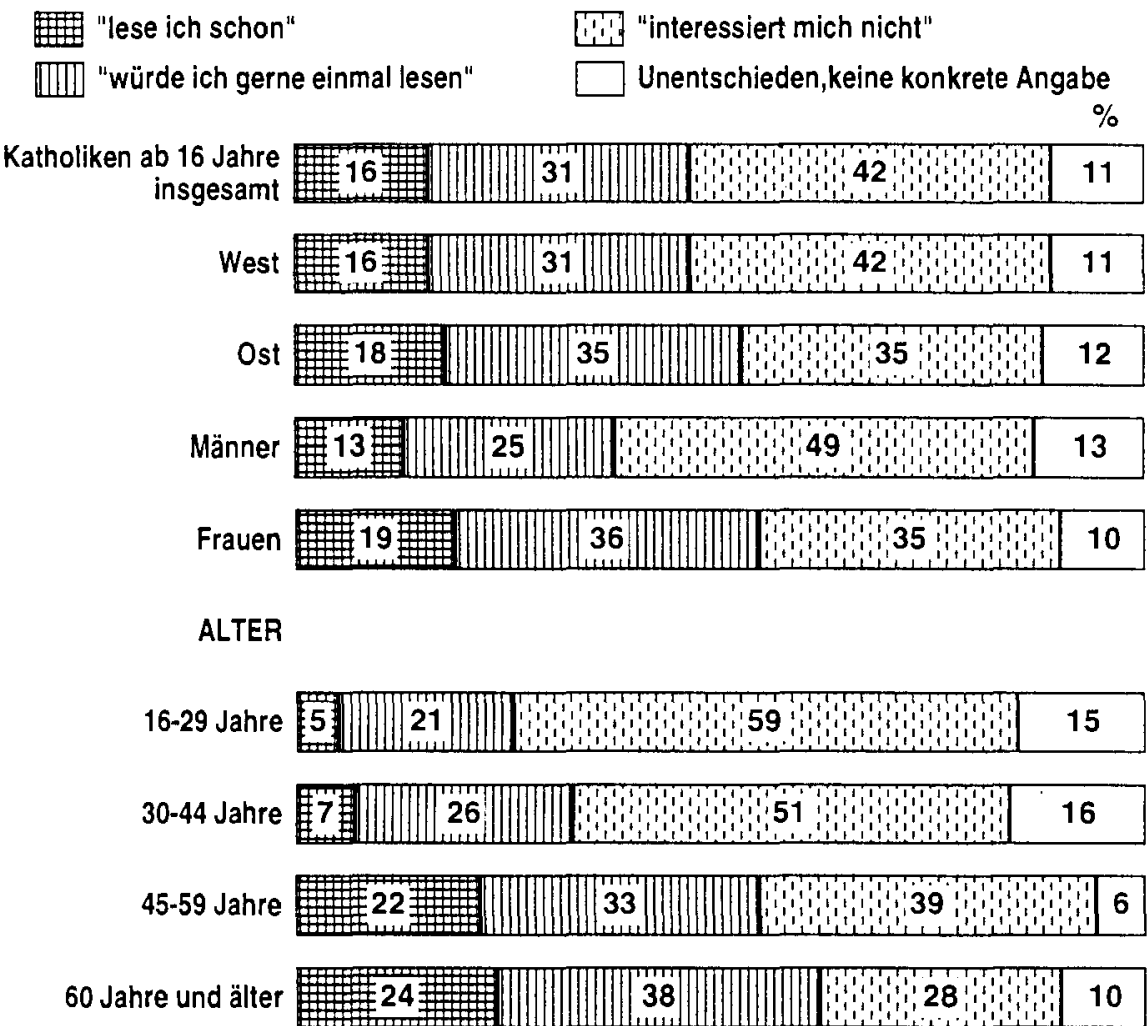

\section{SCHULBILDUNG}

Einfache Schule

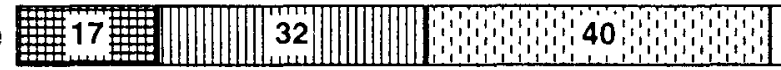

Höhere Schule

世14井




\section{Bereits gewonnene Leser und psychologisches Potential für kirchliche oder christliche Zeitungen, Zeitschriften}

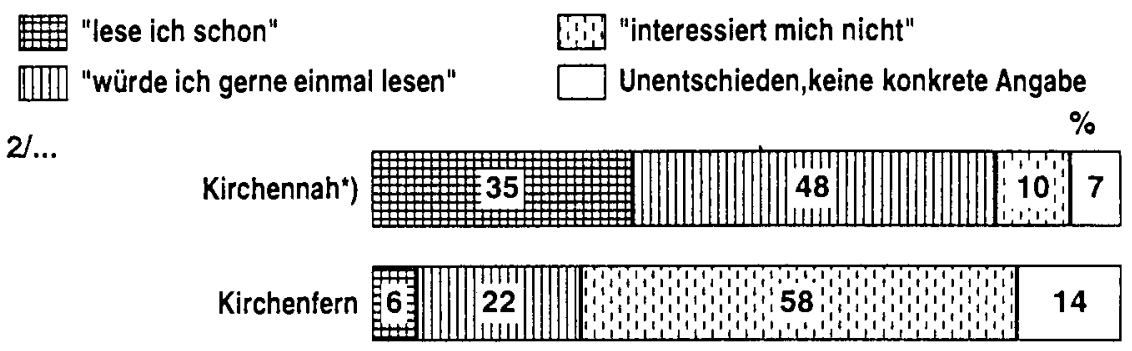

INTERESSE AN KIRCHE UND

GLAUBEN
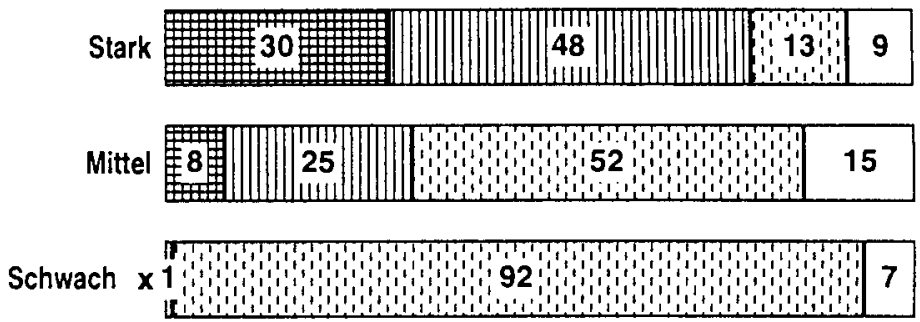

"Bin gläubiges Mitglied meiner

Kirche und stehe zu ihrer

Lehre"

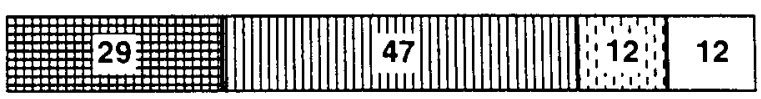

"Ich fühle mich als Christ, aber die Kirche bedeutet mir nicht

viel"

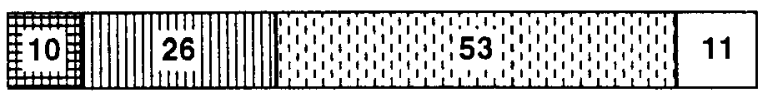

"Ich habe meine eigenen

Glaubensansichten ganz

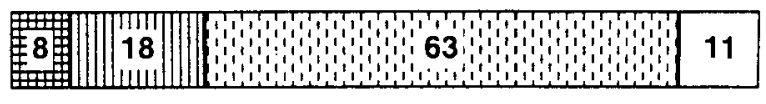

unabhängig von der Kirche

*) Katholiken, die jeden, fast jeden Sonntag zur Kirche gehen

Quelle: Allensbacher Archiv, IfD-Umfrage 6010, Jan. 1995 
Ausgesprochen gering ist dagegen das Interesse der Katholiken an Beiträgen

- ,Aus dem Leben des Bistums' (14\%).

Hier wird erkennbar, daß die Diözese für viele Katholiken keine geeignete Identifikations- bzw. Interessenebene darstellt, so daß die Bezeichnung bzw. das Selbstverständnis als Zeitung des Bistums bzw. des Bischofs die Beachtungs- und Verbreitungschancen in Teilen des Leserpotentials hemmen kann. Die Leser der Kirchenzeitungen wie auch die Katholiken insgesamt interessieren sich in erster Linie für die ,Kirche', für Stellungnahmen zu Glaubensfragen und wichtigen gesellschaftlichen Themen sowie für die eigene Kirchengemeinde, im Nahbereich, dagegen nur wenig für die Bistumsebene. ${ }^{14}$

\section{Die Perspektiven der Kommunikatoren}

Die befragten Bischöfe, Verleger und Chefredakteure stimmen mit deutlicher Mehrheit der These zu ,Man muß die Bistumszeitung stärker an den wirklichen Leserbedürfnissen orientieren' (Bischöfe: $68 \%$, Verleger: $88 \%$, Chefredakteure: $68 \%$ ). In weiten Bereichen besteht zwischen den befragten Bischöfen, Verlegern und Chefredakteuren Konsens über die Aufgaben und Ziele der Bistumspresse und auch Konsens darüber, daß diese Aufgaben von der Bistumspresse weitgehend erfüllt werden.

$\mathrm{Zu}$ diesen Konsenspunkten ohne größeren zusätzlichen Handlungsbedarf zählen

- ,Sollte Hilfe und Orientierung im Glauben geben';

- ,Sollte der Verkündigung des Glaubens dienen';

- Sollte zu aktuellen Problemen aus christlicher Sicht Stellung nehmen';

- Sollte gesellschaftliche Vorgänge und Entwicklungen kommentieren';

- Sollte ausgewogen sein, nicht einseitig berichten'.

Bei einer Reihe anderer Forderungen an die Bistumszeitung besteht weitgehend Konsens über die Erfordernisse, zugleich entspricht hier die bisherige Realisierung noch nicht voll den Erwartungen. Dies gilt z.B. für die Forderungen

- Sollte die Gemeinschaft innerhalb der Diözese stärken';

- ,Sollte den Menschen Mut machen, Hoffnung geben';

- ,Sollte viele Hintergrundberichte aus dem kirchlichen Leben enthalten';

- Gute Kommentare'.

14 Siehe dazu auch Tabelle 6 auf Seite 188. 
Weitere Forderungen, die von allen für wichtig erachtet, aber noch nicht ausreichend erfüllt sind:

- ,Sollte den Lesern helfen, sich im Leben zurechtzufinden';

- Sollte über die Pfarrgemeinde vor Ort berichten'.

Der Anteil der Exklusivnachrichten in der Kirchenzeitung, die man anderswo - vor allem in säkularen Medien - nicht findet, stellt Bischöfe, Verleger, aber auch Chefredakteure noch nicht voll zufrieden.

Neben vielen Konsenspunkten, die in der Bistumszeitung teils schon ausreichend verwirklicht, teils noch verbesserungsbedürftig sind, besteht bei anderen Forderungen mehr oder minder ausgeprägter Dissens zwischen Bischöfen, Verlegern und Chefredakteuren.

Die Bischöfe betonen stärker ,Versöhnung, Harmonie', manche Chefredakteure und vor allem Verleger sehen dagegen eher ein Übermaß an Harmonie in der Bistumszeitung, wünschen sich offensichtlich mehr lebendige Auseinandersetzung im Blatt.

Die Chefredakteure betonen stärker die Funktion der Bistumspresse als Forum für den innerkirchlichen Dialog. Offensichtlich empfinden die Bischöfe eher ein Übermaß, kein Defizit an innerkirchlicher Kritik in der Bistumszeitung. Sie befürworten beides, den Standpunkt des Papstes und auch davon Abweichendes ins Bistumsblatt $z u$ bringen. Aber nach Einschätzung jedes dritten Bischofs hat Kirchenkritisches in der Bistumszeitung ein Übergewicht gewonnen, während viele Chefredakteure und Verleger hier noch einen Nachholbedarf erkennen.

Bei der Frage, welche Maßnahmen Erfolg versprechen und geeignet sind, neue Leser für die Bistumszeitung zu gewinnen (Schaubild C), besteht in wesentlichen Punkten Konsens zwischen Bischöfen, Verlegern und Chefredakteuren:

- ,Mehr Lebenshilfe zu Problemen des Alltags';

- 'Mehr vertiefende Hintergrundinformationen liefern';

- ,Auch kritische, abweichende Meinungen zu Wort kommen lassen' stehen im Maßnahmenkatalog ganz obenan.

Auch

- ,mehr Nachrichten aus den einzelnen Gemeinden' und

- in den Meinungsbeiträgen eindeutig Stellung nehmen` werden als sehr wichtig erachtet.

Bei aller Einsicht, um eine stärkere Berücksichtigung der Leserbedürfnisse nicht herumzukommen, würde jeder zweite Bischof $(46 \%)$ eine stärkere Konzentration auf kirchliche, christliche Themen begrüßen, nur wenige Verleger (12\%) und keiner der befragten Chefredakteure stimmt dieser Themengewichtung zu. 


\section{WELCHE MASSNAHMEN VERSPRECHEN ERFOLG?}

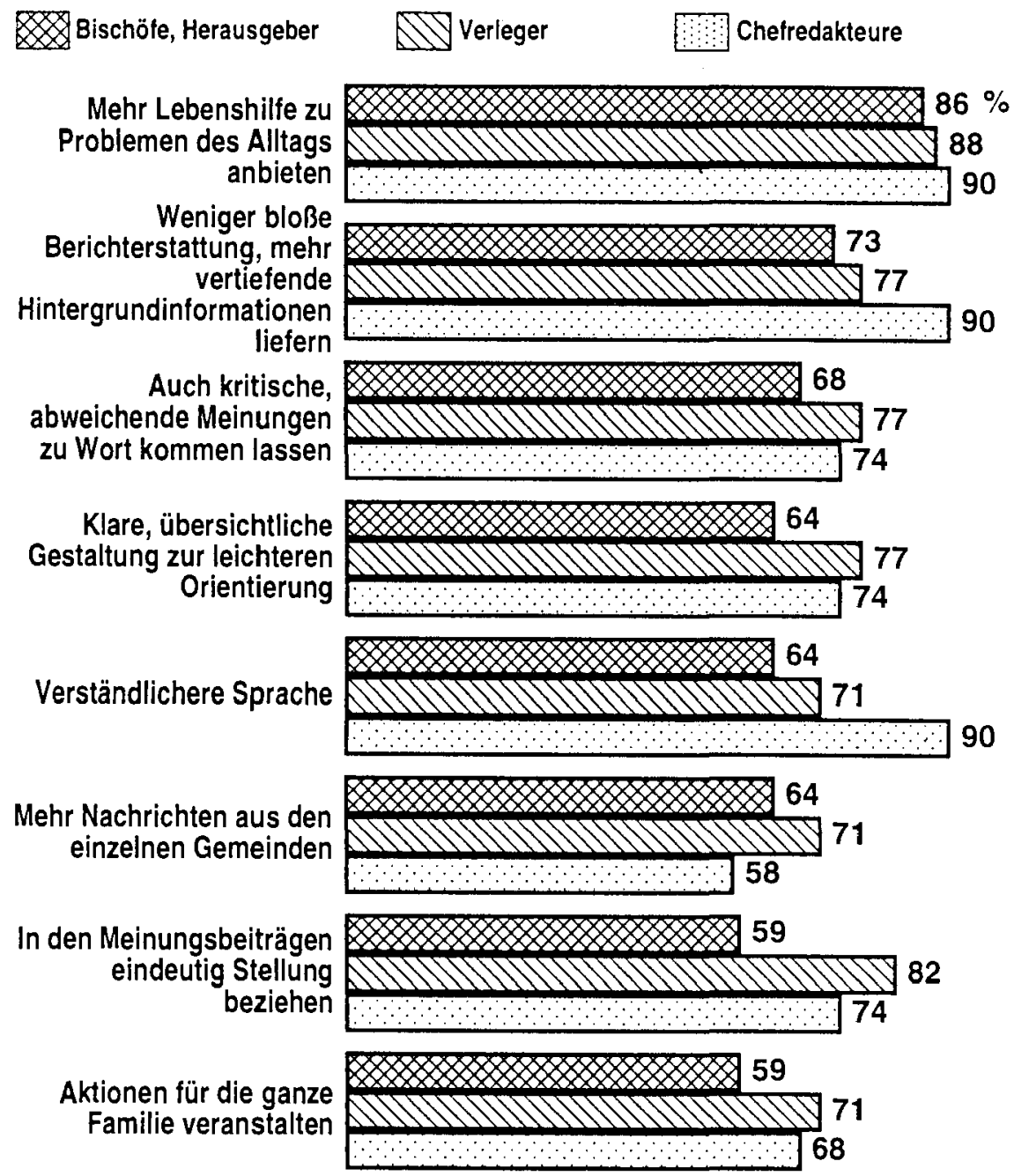




\section{WELCHE MASSNAHMEN VERSPRECHEN ERFOLG?}

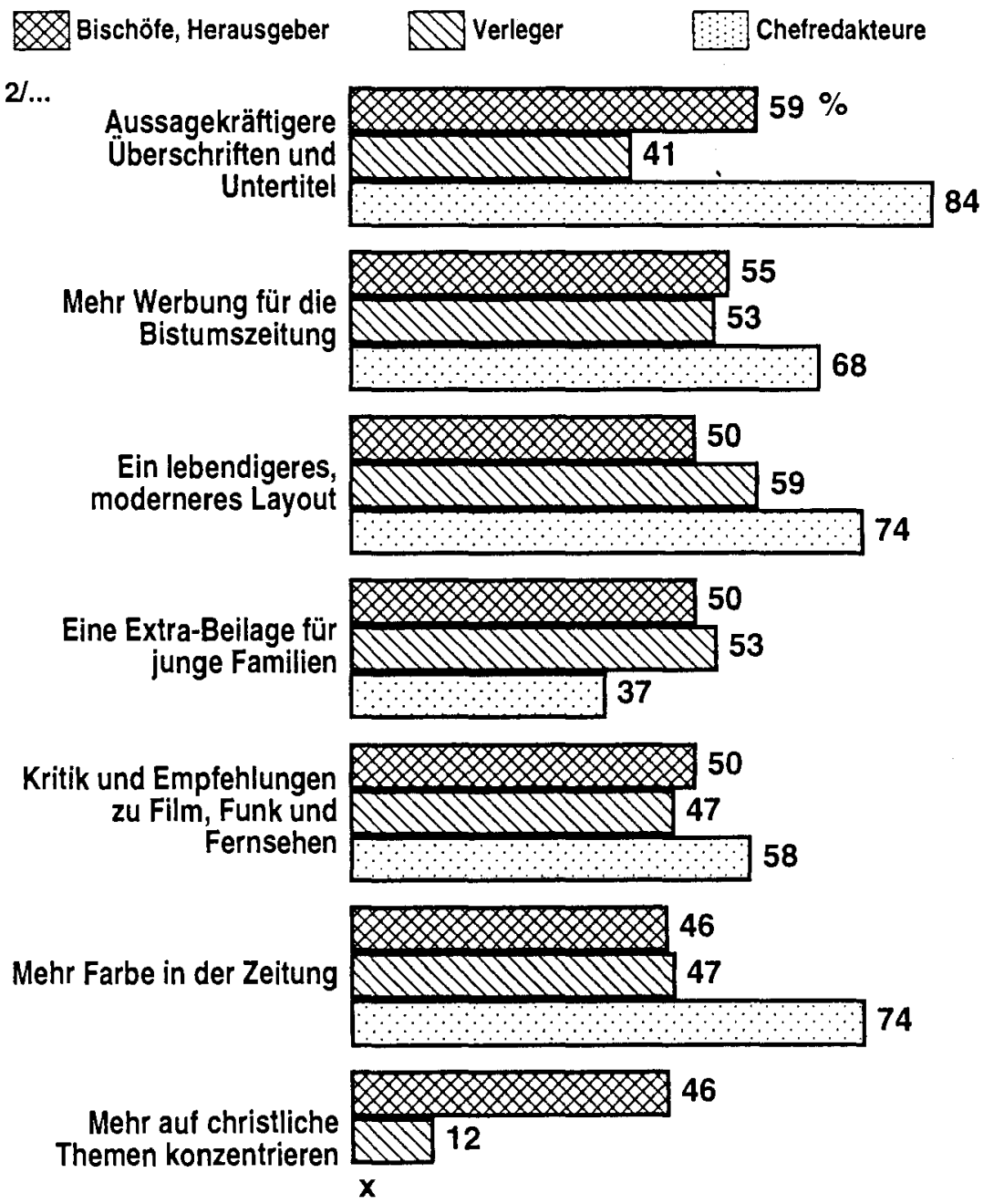




\section{WELCHE MASSNAHMEN VERSPRECHEN ERFOLG?}
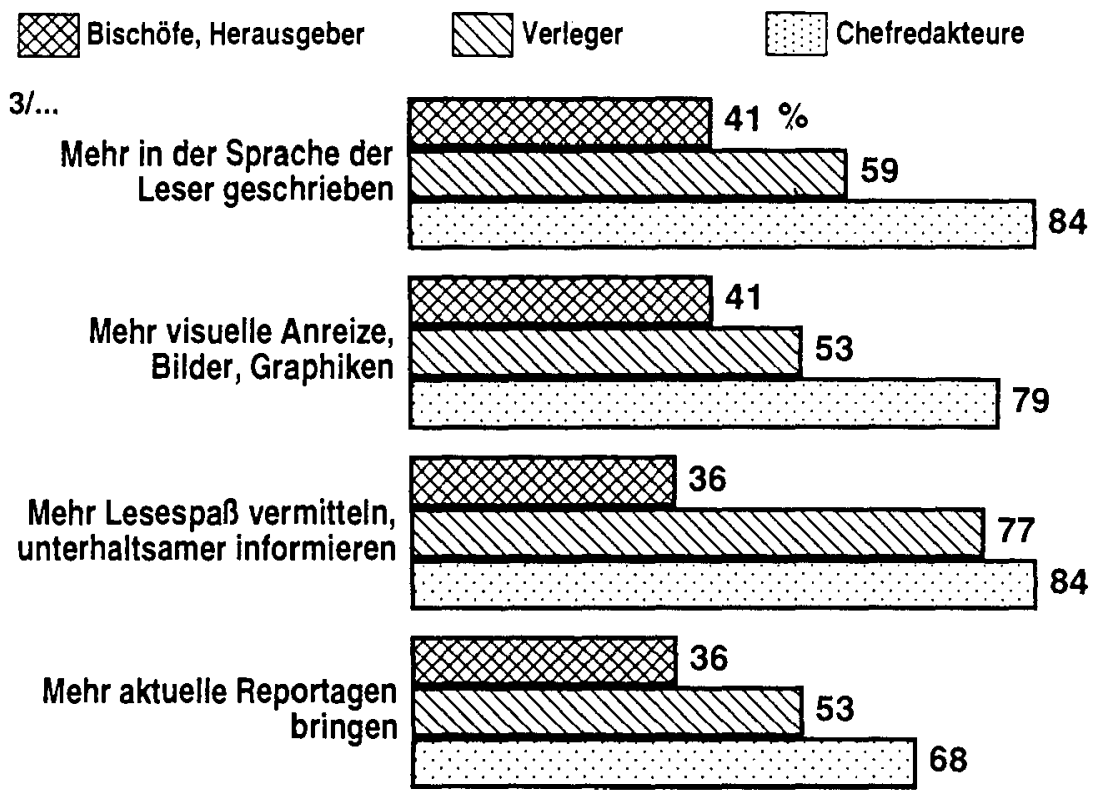

Klare Kennzeichnung einzelner Sparten,

Rubriken durch Symbole, Indexfarben usw.

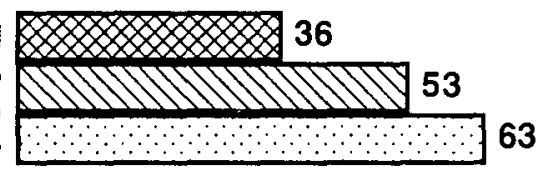

Günstigerer Preis $x$

\section{6}
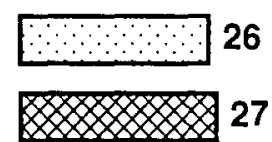

Kürzere, knappere Artikel

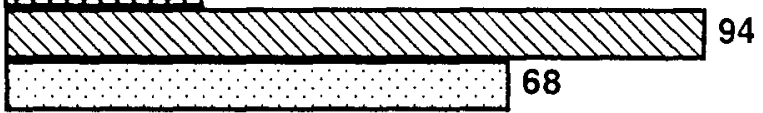




\section{WELCHE MASSNAHMEN VERSPRECHEN ERFOLG?}

Bischöfe, Herausgeber DVu Verleger

$4 / \ldots$

Den Beiträgen kurze Vorspanne voranstellen
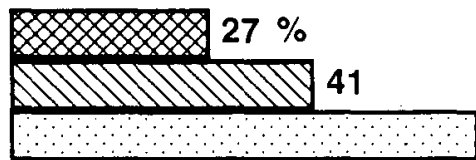

Lockerer, modernerer Sprachstil

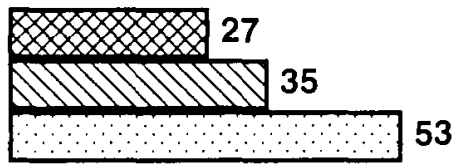

Der Redaktion mehr journalistische Freiheit geben
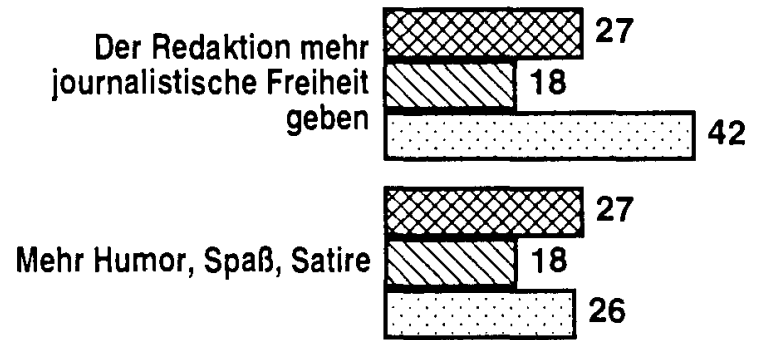

Mehr säkulare Themen anbieten

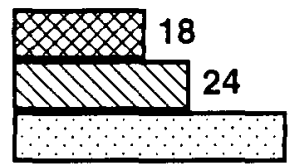

Unterhaltungsbeiträge Mehr
eiträge
z.B. bringen, wie z.B. Geschichten, Erzählungen,
Romane
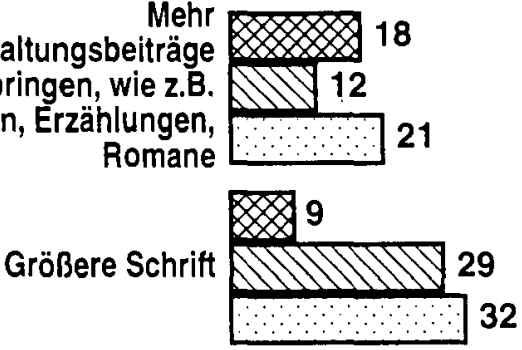

Quelle: Allensbacher Archiv, IfD-Umfrage 1467 
Unmittelbar Nützliches, Ratgeber- und Serviceleistungen, wie z.B. Tips für Haus und Garten, was mit dazu beitragen kann, die Leser-Blatt-Bindung in bestimmten Zielgruppen zu verstärken, wird von vielen Bischöfen eher als lästiges Beiwerk empfunden - wahrscheinlich aus Sorge, daß durch allzuviel davon der zentrale pastorale Auftrag der Bistumszeitung gefährdet werden könnte.

Auch versprechen sich nur wenige Bischöfe etwas davon, ,mehr Lesespaß zu vermitteln, unterhaltsamer $\mathrm{zu}$ informieren' $(36 \%)$, was Chefredakteure (48\%) und Verleger (77\%) mit großer Mehrheit fordern.

Große Hoffnungen setzen dagegen auch die Bischöfe auf optische und sprachliche Verbesserungen in der Kirchenzeitung, wie z.B. ein lebendigeres, moderneres Layout sowie eine verständlichere Sprache.

\section{Konvergenz oder Divergenz der Perspektiven?}

Inwieweit stimmen die Perspektiven der verschiedenen Kommunikatorund Rezipientengruppen sowie die Schlußfolgerungen aus der Inhaltsanalyse ${ }^{15}$ überein, wo gibt es erkennbar Unterschiede? Vorab eine Klärung der Standpunkte: die professionelle Kritik der Publizistikwissenschaftler, an der Meßlatte ,moderner Tageszeitungsjournalismus' orientiert, die Perspektiven der Herausgeber, der Verleger und der Chefredakteure als ,Blattmacher' und die Sichtweise des Durchschnittslesers haben jeweils eigene Qualität und damit eigenes Gewicht. Man muß sich davor hüten, Abonnenten und Abbesteller zu Experten zu machen. Man darf keine konkreten Gestaltungsrezepte von ihnen erwarten, das würde sie überfordern. Wichtig sind ihre subjektiven Eindrücke und Erfahrungen, möglichst spontan und ungeschminkt, nicht daran orientiert, was sie glauben, was von ihnen als Antwort erwartet wird, welche Antworten ,sozial erwünscht' sind. Ihre Ansichten und Meinungen sind für ihr Verhalten im Medienmarkt, ob die Bistumszeitung weiterabonniert oder abbestellt wird, entscheidend. Insofern ist es wichtig, z.B. die Wunschvorstellungen der Kommunikatoren oder die professionelle Kritik der Kommunikationswissenschaftler mit den Urteilen und Empfindungen des Durchschnittslesers oder z.B. auch der Priester und Vertreter katholischer Laiengremien zu konfrontieren. Dabei geht es nicht um die Entscheidung, welche Sichtweise richtig oder falsch ist, vielmehr darum, aus möglichen Divergenzen zwischen verschiedenen, subjektiven Wahrheiten' Schlußfolgerungen zu ziehen, unzutreffende Annahmen und gegebenenfalls auch Maßnahmen oder geplante Strategien zu korrigieren.

15 Siehe dazu den Beitrag von H. M. Kepplinger und S. Chr. Ehmig in diesem Heft. 
Die Kritik der Publizistikwissenschaftler an Sprache (bei einigen Bistumszeitungen zu getragen-frömmelnd) und Layout der Kirchenzeitungen (überwiegend ',konservativ') wird von den Rezipienten so nicht geteilt. Aber man muß hier differenzieren: die meist schon langjährigen, überwiegend älteren Stammleser sind mit der gewohnten Bistumszeitung in der Regel zufrieden, finden die Bistumszeitung auch angenehm zu lesen. Dagegen üben die wenigen jüngeren Abonnenten, die überhaupt gewonnen und gehalten werden konnten, daran häufiger Kritik, und auch jüngere, unter-50jährige Katholiken, die zum psychologischen Interessentenpotential zählen, haben höhere Ansprüche an Sprache und Layout. Dies gilt auch für Priester und Laienvertreter. Damit wird die professionelle Kritik an Sprachstil und Gestaltung durch die Ergebnisse der Rezipientenbefragungen nicht widerlegt, aber in ihrer Bedeutung relativiert.

Besondere A Aktualitätsdefizite werden von den Lesern nicht beklagt. Wahrscheinlich antizipieren die Leser die begrenzteren Möglichkeiten eines nichttagesaktuellen Mediums. Den Abonnenten ist im Zweifelsfalle Vertiefung und Hintergrund ohnehin wichtiger als größtmögliche Aktualität.

Auch der von Kepplinger kritisierte ,Mangel an spezifisch christlicher Sichtweise wird von den Lesern so nicht wahrgenommen. $\mathrm{Daß}$ die Bistumszeitung "zu aktuellen Problemen aus christlicher Sicht Stellung nimmt", wünschen sich $70 \%$ der Abonnenten, darunter auch junge Abonnenten in hohem Anteil (57\%). Fast gleich viele Abonnenten sehen diese Erwartung in ihrer Kirchenzeitung erfüllt (69\%). Auch aus Sicht der Bischöfe, Chefredakteure und Verleger besteht hier kein besonderer Handlungsbedarf. Allerdings sollte bei dieser Gesamtbetrachtung nicht übersehen werden, daß das Ausmaß an ,Durchdringung gesellschaftlicher Themen aus spezifisch christlicher Sicht' bei den verschiedenen Bistumszeitungen differiert. Bei einigen Kirchenzeitungen wird dies auch von den Abonnenten als Defizit empfunden. Kepplingers Forderung, einer spezifisch christlichen Sichtweise als Maßnahme zur eigenständigen Profilierung der Bistumszeitungen besondere Aufmerksamkeit zu widmen, ist deshalb mit Nachdruck zu unterstreichen.

Anhand der Ergebnisse der Inhaltsanalyse kritisiert Kepplinger den nach seiner Ansicht zu hohen Anteil kirchlicher Themen in der Bistumszeitung, z.B. daß die Welt des Klerus - insbesondere personale und organisatorische Bezüge zur Kirche - im Verhältnis zur Lebenswelt der Laien zu breiten Raum einnimmt. Dem steht entgegen, daß vor allem Berichte aus der Kirchengemeinde, aber auch ,Aus dem Bistum' sowie Personalia der Kirche zumindest von den meist älteren Stammlesern zufriedenstellend genutzt werden. Sie empfinden die Bistumszeitung offensichtlich nicht abwertend als ,Kirchliches Vereinsblatt'. Aber die jüngeren Abonnenten und auch Katholiken, die zum psychologischen Interessentenpotential zählen, interessieren sich erkennbar weniger dafür. 
Abonnenten einer Bistumszeitung -

$\begin{array}{ccccc}\text { insge- } & \text { unter } & 40-49- & 50-59- & 60 \text { jährige } \\ \text { samt } & \begin{array}{c}40 \text { jäh- } \\ \text { rige }\end{array} & \begin{array}{c}\text { jäh- } \\ \text { rige }\end{array} & \begin{array}{c}\text { jäh- } \\ \text { rige }\end{array} & \text { u.ältere } \\ \% & \% & \% & \% & \%\end{array}$

Es lesen im allgemeinen

immer, fast immer in der Bistums-

zeitung -

Berichte aus meiner Kirchen-

gemeinde.

53

62

64

Stellungnahmen, Aussagen des

Bischofs.

27

39.

Personalia aus der Kirche

(z. B. Ernennungen, Ehrungen,

Jubiläen, Todesfälle).

27

41

Berichte aus dem Leben des

Bistums

28

33

40

Aus dem Leben der Weltkirche

24.

36.

40.

$\begin{array}{ccc}\begin{array}{c}\text { Abonnen- } \\ \text { ten einer }\end{array} & \text { Nichtleser einer Bistumszeitung, die- } \\ \begin{array}{c}\text { Bistums- } \\ \text { zeitung }\end{array} & \begin{array}{c}\text { zum Interes- } \\ \text { sentenpoten- } \\ \text { tial zählen }\end{array} & \begin{array}{c}\text { sich nicht für } \\ \text { eine Bistums- } \\ \text { zeitunginteres- } \\ \text { sieren } \\ \%\end{array} \\ \% & \%\end{array}$

Es interessieren sich für -

Beiträge aus dem Leben des

Bistums

$17 \ldots \ldots \ldots \ldots \ldots \ldots \ldots \ldots \ldots \ldots \ldots \ldots \ldots$

Für die meisten Katholiken ist die eigene Kirchengemeinde die eigentliche Identifikations- und Interessenebene. Die Bindung an das Bistum ist deutlich geringer, was allerdings beachtliches Interesse schon der ab 40jährigen - an Stellungnahmen und Aussagen des Bischofs nicht ausschließt.

Wir erfahren aus der Inhaltsanalyse nicht, in welchem Umfang die Kirchenzeitungen den Standpunkten der Amtskirche, z.B. von Papst und Bischof, auf der einen und innerkirchlicher Diskussion auf der anderen Seite Raum geben. Hier jedoch liegt der eigentliche Dissens: Während viele Bischöfe eher ein Zuviel an innerkirchlicher Kritik in den Kirchenzeitungen wahrnehmen, wünschen sich viele Abonnenten und 
Abbesteller, vor allem aber auch Priester und Vertreter katholischer Laiengremien davon mehr.

Auch die Bischöfe erwarten, wie alle anderen Gruppen, in hohem Anteil Mut von den Kirchenzeitungen, auch Themen aufzugreifen, die in der Kirche umstritten sind (Idealbild, so sollte die Bistumszeitung sein: $73 \%$ ), und nur jeder zweite Bischof hält seine Bistumszeitung schon für ausreichend mutig (Realbild, das trifft auf die Bistumszeitung zu: $50 \%)$.

„Sollte eine mutige Zeitung sein, auch Themen aufgreifen, die in der Kirche umstritten sind":

$\begin{array}{lccccccc} & \begin{array}{c}\text { Bischöfe, } \\ \text { Heraus- } \\ \text { geber } \\ \%\end{array} & \text { Verleger } & \begin{array}{c}\text { Chef- } \\ \text { redak- } \\ \text { teure } \\ \%\end{array} & \begin{array}{c}\text { Abon- } \\ \text { nenten }\end{array} & \begin{array}{c}\text { Abbe- } \\ \text { steller }\end{array} & \text { Priester } & \begin{array}{c}\text { Laien- } \\ \text { vertreter }\end{array} \\ & 73 & 88 & 95 & 73 & 59 & 72 & 91 \\ \text { Idealbild: } 16 & 70 & 71 & 84 & 44 & 20 & 37 & 42 \\ \text { Realbild:17 } & 50 & -17 & -11 & -29 & -39 & -35 & -49 \\ \text { Differenz: } & -23 & -17 & \end{array}$

Doch deutet vieles darauf hin, daß Bischöfe in den Bistumszeitungen eher Mut vermissen, den Standpunkt von Papst und Bischof entschieden zu vertreten, während es den Kirchenzeitungen aus Sicht der Abonnenten, Abbesteller, Priester und Laienvertreter eher an Mut mangelt, von der offiziellen Linie der Kirche abweichende Stellungnahmen zu Wort kommen zu lassen und sich mit aus ihrer Sicht ,fortschrittlicheren' Tendenzen in der Kirche auseinanderzusetzen.

"Sollte entschieden die Haltung von Papst und Bischof vertreten":

$\begin{array}{lccccccc} & \begin{array}{c}\text { Bischöfe, } \\ \text { Heraus- } \\ \text { geber } \\ \%\end{array} & \% & \text { Verleger } & \begin{array}{c}\text { Chef- } \\ \text { redak- } \\ \text { teure } \\ \%\end{array} & \begin{array}{c}\text { Abon- } \\ \text { nenten }\end{array} & \begin{array}{c}\text { Abbe- } \\ \text { steller }\end{array} & \begin{array}{c}\text { Priester } \\ \text { Lertreter } \\ \text { verien- }\end{array} \\ \text { Idealbild: } & 59 & 12 & 21 & 32 & \% & \% & \% \\ \text { Realbild: } & 36 & 18 & 11 & 47 & 48 & 35 & 42 \\ \text { Differenz: } & -23 & +6 & -10 & +15 & +31 & +8 & +27\end{array}$

\footnotetext{
16 Idealbild: So sollte die Bistumszeitung sein

17 Das Realbild: "Das trifft auf meine Kirchenzeitung $\mathrm{zu}^{\prime}$ wurde jeweils als faktische Aussage formuliert, hier z.B. ,Ist eine mutige Zeitung, greift auch Themen auf, die in der Kirche umstritten sind'.
} 
"Sollte auch Meinungen zulassen, die von der offiziellen Linie der Kirche abweichen":

$\begin{array}{lccccccc} & \begin{array}{c}\text { Hischöfe, } \\ \text { Heraus- } \\ \text { 8eber } \\ \%\end{array} & \text { Verleger } & \begin{array}{c}\text { Chef- } \\ \text { redak- } \\ \text { teure } \\ \%\end{array} & \begin{array}{c}\text { Abon- } \\ \text { nenten }\end{array} & \begin{array}{c}\text { Abbe- } \\ \text { steller }\end{array} & \begin{array}{c}\text { Priester } \\ \text { vertreter }\end{array} & \text { Laien- } \\ & \% & \% & \% & \% & \% \\ \text { Idealbild: } & 59 & 71 & 95 & 53 & 49 & 62 & 77 \\ \text { Realbild: } & 68 & 82 & 95 & 39 & 17 & 51 & 44 \\ \text { Differenz: } & +9 & +11 & +0 & -14 & -32 & -11 & -33\end{array}$

"Setzt sich zuwenig mit fortschrittlichen Tendenzen in der Kirche auseinan$\operatorname{der}^{\prime \prime} 18$

$\begin{array}{cccccccc} & \begin{array}{c}\text { Bischöfe, } \\ \text { Heraus- } \\ \text { geber }\end{array} & \text { Vetleger } & \begin{array}{c}\text { Chef- } \\ \text { redak- } \\ \text { teure }\end{array} & \begin{array}{c}\text { Abon- } \\ \text { nenten }\end{array} & \begin{array}{c}\text { Abbe- } \\ \text { steller }\end{array} & \text { Priester } & \begin{array}{c}\text { Laien- } \\ \text { vertreter }\end{array} \\ \text { Realbild: } & 5 & 24 & 11 & 27 & 32 & 33 & 50\end{array}$

Offensichtlich empfinden Bischöfe eher ein Übermaß, kein Defizit an innerkirchlicher Kritik in der Bistumszeitung. Sie befürworten beides, den Standpunkt des Papstes und auch davon Abweichendes ins Bistumsblatt zu bringen. Aber nach Einschätzung jedes dritten Bischofs hat Kirchenkritisches offensichtlich in der Bistumszeitung ein Übergewicht gewonnen, während viele Chefredakteure und Verleger, aber auch Priester und vor allem Vertreter katholischer Laiengremien hier noch einen Nachholbedarf erkennen (Tabelle 4).

$\overline{18} \mathrm{Zu}$ dieser negativen Aussage wurde kein Idealbild ermittelt. 


\begin{abstract}
FRAGE: "Was halten Sie persönlich für wichtiger, worauf sollte die zeitung Ihres Bistums in Zukunft größeres Gewicht legen, die Haltung von Papst und Bischof in der Bistumszitung entschiedener zu vertreten oder sich stärker für Meinungen zu offnen, die manches an der Lehrmeinung der Kirche kritisieren?"
\end{abstract}

$\begin{array}{ccc}\text { Bischöfe, } & \text { Verleger } & \begin{array}{c}\text { Chef- } \\ \text { redakteure }\end{array} \\ \text { Herausgeber } & 8 & 8\end{array}$

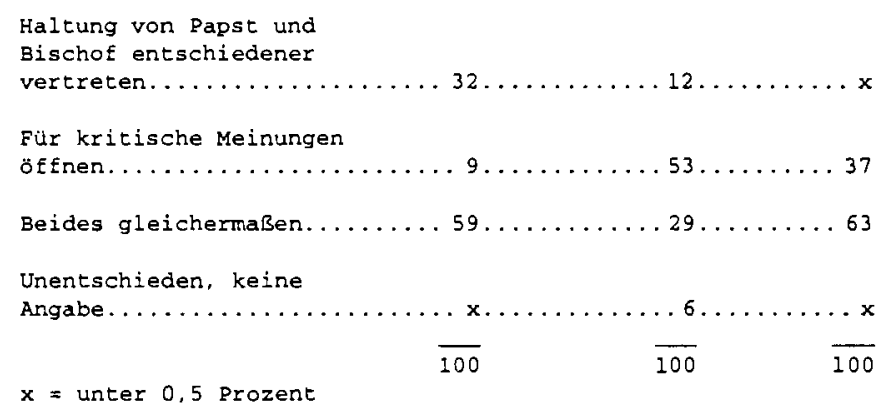

QUELLE: Allensbacher Archiv, IfD-UmErage 1467

Aus Sicht vieler Rezipienten ist die Kirchenzeitung zu sehr Sprachrohr der Kirchenleitung' und zu wenig ,Forum für die innerkirchliche Diskussion'. Sie sind durchaus an Stellungnahmen der Kirchenleitung, insbesondere auch zu gesellschaftlichen Themen, interessiert. Aber zusätzlich möchten sie auch davon abweichende Stellungnahmen, innerkirchliche Kritik und Berichte über innerkirchlich kontrovers diskutierte Themen, wie z.B. Pflichtzölibat, Stellung der Frau in der Kirche, im Bistumsblatt lesen, davon nicht nur aus säkularen Medien erfahren. Kompetente und faire Auseinandersetzung in der Bistumszeitung würde ihre Glaubwürdigkeit zweifellos erhöhen und die Kirchenzeitung für breitere Katholikenkreise lesenswert machen.

Kepplingers auf die Erkenntnisse aus der Inhaltsanalyse gestützte Kritik an zuviel Kirchenbezug gilt deshalb nicht generell für alle Bistumszeitungen. Sie ist dort berechtigt, wo z.B. auf die Vollständigkeit der Bistumsberichterstattung (z.B. als Chronistenpflicht) mehr Wert gelegt wird als auf die gezielte Selektion, journalistische Bearbeitung und Publikation für viele Leser interessanter Lesestoffe. Für den Leser interessant sind vor allem auch kontrovers diskutierte Themen sowie Beiträge, die seine Probleme aufgreifen, die ihm Glaubens-, Orientierungs- und Lebenshilfe geben, vor allem - aber nicht nur - im eigenen lokalen oder regionalen Umfeld. 
Kepplingers Forderungen nach so viel lokalen Bezügen wie möglich, nach mehr Lebenshilfe und nach einer positiveren Ausstrahlung der Kirchenzeitungen sind in allen Befragtengruppen unumstritten. Auch die Bischöfe wünschen, daß die Kirchenzeitungen mehr Mut machen, den Menschen Hoffnung geben sollten. Dies würde nicht zuletzt auch zu mehr Lesefreude beitragen.

\section{Was Bistumszeitungen mit unterdurchschnittlichem Auflagenrück- gang auszeichnet}

Ein Vergleich der Auflagenentwicklung der verschiedenen Kirchenzeitungen zeigt, daß es mehreren Bistumszeitungen vergleichsweise gut gelungen ist, ihre Position zu behaupten. Sechs Bistumszeitungen haben im Jahresvergleich 4. Quartal 1993/4. Quartal 1994 unterdurchschnittlich, d.h. weniger als $3 \%$ an Auflage verloren: Der Bonifatiusbote (Fulda) ${ }^{19}$, das Konradsblatt (Freiburg), Glaube und Leben (Mainz), das Passauer Bistumsblatt, der Kirchenbote (Osnabrück) sowie die Kirchenzeitung für das Bistum Eichstätt. Sechs Bistumszeitungen haben etwa durchschnittliche Auflagenverluste ( 3 bis $6 \%$ ) hinnehmen müssen, sechs überdurchschnittliche ( $7 \%$ und mehr) ${ }^{20}$

Gibt es aus der vergleichenden Situationsanalyse Hinweise, die den relativen Erfolg der sechs Bistumszeitungen mit sowohl kurzfristig als in der Regel auch langfristig unterdurchschnittlichem Auflagenrückgang erklären können?

Ein Vergleich der Strukturmerkmale der Verbreitungsgebiete zeigt, daß es in katholisch geprägten Bistümern in eher ländlichen Gebieten ohne großstädtische Zentren offensichtlich besser gelingt, die Auflage in etwa zu halten, als in Diasporasituationen sowie bei einem höheren Anteil großstädtischer Bevölkerung (Tabelle 5).

19 Als einziges Bistumsblatt hat der Bonifatiusbote 1994 an Auflage hinzugewonnen $(+2,2 \%)$.

20 Die kurzfristige Auflagenentwicklung korreliert in der Regel auch mit der langfristigen Auflagenentwicklung im 10-Jahres-Vergleich (siehe Tabelle 5). 
Werkmale der unterschiedlich erfolgreichen Bistumszeitungen. Bistumszeitungen mit unterdurchschnitthichen Auflagenverlusten sird eher in katholisch gepragter Diozesen chce aroßstadtische zentren. verbreitet
Tabelle 5

Bundeszepublik Deutschland

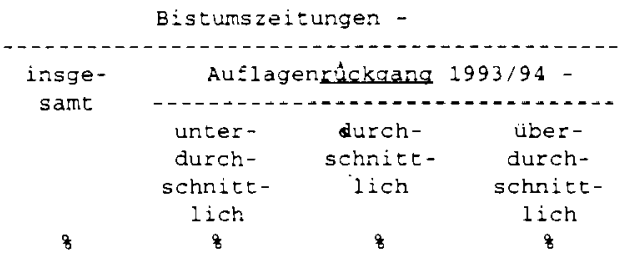

\section{Huflagentuckgang langexistig}

$1985 / 1994 \ldots *$

unterdurchschnittlich......28

durchschnitelich......... 28

Überdurchschnit=lich.......44

In katholischer Region...... 33

In Mischregion............445

In der Diaspora.......... 22

Mit großstadtischem Zentrum. . 50 Ohne grobstädtisches

zentrum............... 50

\section{Qttsgroße:}

Von den Abonnenten leben

in Gemeinden -

unter 5000 Einivother........16 z'vischen 5000 und $20.000 \mathrm{Ein-}$

wohner............... . 27

zwischen 20.000 und 100.000

Einwohner..................... 32

über 100.000 Einwohner.....25

$\overline{100}$

Anzar: der Eistumszeltungen $\mathrm{n}=18$

*) Berlin und Leipzig 1991/1994

QUELLE: Al lensbacher Archiv, IfD-Umfrage 1457
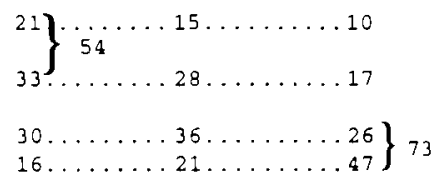

$\overline{100} \quad \overline{100} \quad \overline{100}$

$6 \quad 6$ 
Die Abonnenten von Kirchenzeitungen mit unterdurchschnittlichen Auflagenverlusten sind weder besonders religiös noch sind sie stärker als die Abonnenten anderer Kirchenzeitungen an Themen wie 'Kirche und Glaube' interessiert. Ihre Bindung an das Bistum ist etwa durchschnittlich. Was sie auszeichnet, ist eher überdurchschnittliches Engagement in ihrer Pfarrgemeinde:

\section{Bistumszeitungen}

\begin{tabular}{|c|c|c|c|}
\hline \multirow{2}{*}{$\begin{array}{l}\text { insge } \\
\text { samt }\end{array}$} & \multicolumn{3}{|c|}{ Auflagenrückgang 1993/94 } \\
\hline & $\begin{array}{l}\text { unterdurch- } \\
\text { schnittlich }\end{array}$ & $\begin{array}{l}\text { durch- } \\
\text { schnittlich }\end{array}$ & $\begin{array}{l}\text { überdurch- } \\
\text { schnittlich }\end{array}$ \\
\hline$\%$ & $\%$ & $\%$ & $\%$ \\
\hline
\end{tabular}

„Ich bin gläubiges Mitglied meiner Kirche und stehe zu ihrer Lehre"

Es gehen in die Kirche jeden, fast jeden Sonntag Bindung an die Pfarrgemeinde eng

Bindung an das Bistum

eng

Es arbeiten in der Pfarrgemeinde aktiv mit

Bei den in der Vergangenheit vergleichsweise erfolgreicheren Bistumszeitungen besteht auch für die Zukunft geringere akute Abwanderungsgefahr:

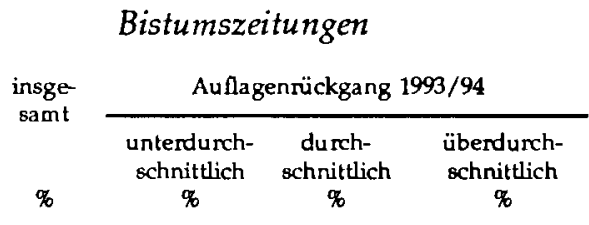

Von den Abonnenten denken aktuell daran, das Abonnement zu kündigen

Zwar sind auch bei den vergleichsweise erfolgreicheren Bistumszeitungen nur sehr wenige junge Abonnenten zu finden, aber es ist ihnen gelungen, mehr noch beruflich Aktive im Alter unter 60 Jahren an sich zu binden: 


\section{Bistumszeitungen}

\begin{tabular}{cccc} 
insge- & \multicolumn{3}{c}{ Auflagenrückgang } \\
\cline { 2 - 2 } & $\begin{array}{c}\text { unterdurch- } \\
\text { schnittlich }\end{array}$ & $\begin{array}{c}\text { durch- } \\
\text { schnittlich }\end{array}$ & $\begin{array}{c}\text { überdurch- } \\
\text { schnittlich }\end{array}$ \\
$\%$ & $\%$ & $\%$ & $\%$
\end{tabular}

Alter der Abonnenten:

16 - 29 Jahre

$30-49$ Jahre

\begin{tabular}{cccc}
1 & 2 & 1 & 1 \\
19 & 24 & 18 & 17 \\
23 & 27 & 21 & 23 \\
25 & 23 & 26 & 24 \\
32 & 24 & 34 & 35 \\
\hline 100 & 100 & 100 & 100
\end{tabular}

Berufstätige

Rentner, Ruhestand

30

39

24

30

45

36

47

53

Verheiratete

Verwitwete

67

73

67

62

22

16

25

23

Anzahl der befragten Abon-

nenten dieser Bistumszei-

tungen $n=$

$\begin{array}{lll}1.871 & 403 & 643\end{array}$

825

Die Abonnenten von Bistumszeitungen mit vergleichsweise gerin'geren Auflagenverlusten lesen die Bistumszeitung häufiger, ,weil man dort Informationen bekommt, die man anderswo nicht erfährt', auch weil sie, in Glaubens- und Kirchenfragen mitreden möchten'. Dagegen bewerten sie Aufmachung und Erscheinungsbild sowie Fotos und Bilder ihrer Bistumszeitung nicht positiver als die Abonnenten von weniger erfolgreichen Bistumszeitungen.

\section{Bistumszeitungen}

\begin{tabular}{|c|c|c|c|}
\hline \multirow{2}{*}{$\begin{array}{l}\text { insge- } \\
\text { samt }\end{array}$} & \multicolumn{3}{|c|}{ Auflagenrückgang 1993/94 } \\
\hline & $\begin{array}{l}\text { unterdurch- } \\
\text { schnittlich } \\
\qquad \%\end{array}$ & $\begin{array}{c}\text { durch- } \\
\text { schnittlich } \\
\%\end{array}$ & $\begin{array}{c}\text { überdurch- } \\
\text { schnittlich } \\
\%\end{array}$ \\
\hline
\end{tabular}

Es lesen die Bistumszeitung „weil man dort Informationen bekommt, die man woanders nicht findet" 58

62

56

"weil ich auch in Glaubensund Kirchenfragen mitreden möchte"

43

37

34

Es bewerten

die Aufmachung, das Erscheinungsbild der Bistumszeitung auf einer Skala von +5 bis -5 im Durchschnitt mit

$+2,7 \quad+2,6 \quad+2,8 \quad+2,6$


die Fotos, Bilder in der

Bistumszeitung im Durch-

schnitt mit

$$
+2,7 \quad+2,8 \quad+2,7 \quad+2,7
$$

Die spontanen Empfehlungen, ohne Antwortvorgaben, was die Redaktion ihrer Kirchenzeitung ändern, verbessern sollte, deuten auf insgesamt größere Zufriedenheit der Abonnenten von erfolgreicheren Bistumszeitungen hin, was Kritik bzw. Verbesserungsvorschläge im einzelnen nicht ausschließt.

\section{Bistumszeitungen}

\begin{tabular}{cccc} 
insge- & \multicolumn{3}{c}{ Auflagennückgang } \\
samt & $\begin{array}{c}\text { unterdurch- } \\
\text { schnittlich }\end{array}$ & $\begin{array}{c}\text { durch- } \\
\text { schnittich }\end{array}$ & $\begin{array}{c}\text { überdurch- } \\
\text { schnittlich }\end{array}$ \\
\cline { 2 - 3 } & $\%$ & $\%$ & $\%$
\end{tabular}

Es empfehlen der Redaktion

das äußere Erscheinungsbild verbessern, Aufmachung ändern 12 die Bistumszeitung interessanter, lebendiger, moderner gestalten den Schreibstil ändern offener sein, nicht so einseitig berichten, auch Kritik zulassen

$\begin{array}{llll}12 & 13 & 11 & 14 \\ 4 & 3 & 5 & 6 \\ 4 & 3 & 4 & 6 \\ 8 & 8 & 7 & 11\end{array}$

Als weiterer wichtiger Erklärungsgrund für relativ erfolgreichere Auflagenentwicklung kommt überdurchschnittliche Werbeaktivität dieser Bistümer hinzu.

\section{Bistumszeitungen}

\begin{tabular}{|c|c|c|c|}
\hline \multirow{2}{*}{$\begin{array}{l}\text { insge- } \\
\text { samt }\end{array}$} & \multicolumn{3}{|c|}{ Aullagenrückgang 1993/94 } \\
\hline & $\begin{array}{l}\text { unterdurch- } \\
\text { schnittlich }\end{array}$ & $\begin{array}{l}\text { dunch- } \\
\text { ochnittlich }\end{array}$ & $\begin{array}{l}\text { überdurch- } \\
\text { schnittlich }\end{array}$ \\
\hline
\end{tabular}

Werbeaktivität 21

überdurchschnittlich durchschnittlich

\begin{tabular}{cccc}
28 & 50 & 17 & 17 \\
39 & 50 & 17 & 50 \\
33 & $\times$ & 66 & 33 \\
\hline 100 & 100 & 100 & 100
\end{tabular}

Die Gegenüberstellung von Bistumszeitungen mit unterschiedlicher Auflagenentwicklung zeigt, daß relativer Erfolg, hier definiert als

21 Einstufung aufgrund der Aussagen der Vertriebs- bzw. Werbeleiter 
unterdurchschnittlicher Auflagenrückgang, nicht monokausal gedeutet werden kann. Vielmehr wirken verschiedene begünstigende bzw. hemmende Faktoren zusammen:

- Günstigere strukturelle Voraussetzungen, wie z.B. hoher Katholikenanteil in der Bevölkerung, katholisch geprägte Mentalität, eher ländlich, klein- oder mittelstädtisch strukturiertes Verbreitungsgebiet ohne großstädtischen Ballungsraum;

- überdurchschnittlich kirchlich aktive, interessierte, keineswegs besonders ,angepaßte', vielmehr zu lebendiger Auseinandersetzung auch über unterschiedliche Positionen in der Kirche bereite Katholiken;

- Angebote in der Kirchenzeitung, die in Form, Sprache, Inhalt den Erwartungen der Abonnenten vergleichsweise gut entsprechen, unterdurchschnittlich Anlaß zu Kritik bieten;

- überdurchschnittliche Werbeaktivität.

Keiner dieser Faktoren ist allein ausschlaggebend für den relativen Erfolg dieser Kirchenzeitungen. So kann zwar besondere Werbeaktivität erfolgreiche Neuakquisitionen erklären, nicht aber überdurchschnittliche Zufriedenheit und geringere Abwanderungsneigung der schon langjährig treuen Abonnenten. Hierfür dürfte eine bessere Übereinstimmung zwischen den Leseerwartungen und den Angeboten in der Kirchenzeitung entscheidend sein.

Insofern gibt es auch keine einfachen, allgemeingültigen Patentrezepte für den Erfolg der Printgattung ,Bistumszeitung،. Vielmehr müssen unter unterschiedlichen Rahmenbedingungen, wie z.B. unterschiedlicher Bevölkerungsmentalität im Süden und Norden, in stark katholisch geprägten Regionen bzw. in der Diaspora oder in gemischtkonfessionellen Gebieten, in eher ländlich strukturierten bzw. eher großstädtischen Verbreitungsgebieten, für in unterschiedlichem Maße kirchlich engagierte Katholiken mit unterschiedlichen Erwartungen an eine Kirchenzeitung jeweils optimale Lösungen für den Einzelfall gesucht werden.

\section{Schlußfolgerungen}

Die vergleichende Situationsanalyse der Bistumszeitungen 1994 hat viele Erkenntnisse aus den Vorgängerstudien auf aktueller Datenbasis bestätigt, vertieft und ergänzt. Zugleich wurden die Perspektiven der Kommunikatoren erstmals differenziert erfaßt. Auch konnte bei der Analyse auf detaillierte Erkenntnisse aus der vergleichenden Inhaltsanalyse der Bistumszeitungen Bezug genommen werden, die zeitlich parallel am Mainzer Institut für Publizistik durchgeführt worden ist. 
a) Optimierung der Kirchenzeitungen für die Kernleser sowie für die nachwachsende Generation der etwa ab-40jährigen Katholiken des Interessentenpotentials

Auf die starke Überalterung und die Konzentration des Publikums der Bistumszeitungen auf den engeren Kreis der regelmäßigen Kirchgänger hat Michael Schmolke schon in seinem Kommentar zur Feldbefragung von 1975 eindringlich aufmerksam gemacht.22 20 Jahre später gewinnt man aus der aktuellen Abonnentenbefragung den Eindruck, daß mit der stark rückläufigen Auflagenentwicklung seither ein Siebungsprozeß verbunden war: die verbliebenen bistumszeitungstreuen Kernleser gehören in noch höherem Anteil als schon damals ermittelt dem Alterssegment der 60jährigen und älteren an, während es in den vergangenen Jahren kaum gelang, Neuabonnenten in der nachwachsenden Katholikengeneration auf Dauer zu gewinnen. Auch zeigt die aktuelle Situationsanalyse, daß die wenigen jüngeren Neuabonnenten in überdurchschnittlichem Anteil schon wieder abwanderungsgefährdet sind.

Im Laufe dieses Siebungsprozesses haben sich offensichtlich vor allem jene ehemaligen Abonnenten von der Kirchenzeitung getrennt, die an ihren Inhalten nicht wirklich interessiert waren, die die Bistumszeitung lediglich aus Tradition oder Gefälligkeit lasen oder wegen eines tatsächlichen oder vermeintlichen sozialen Drucks (z. B. "Weil es sich hier so gehört", "Was würden sonst der Pfarrer, die Nachbarn von uns denken").

Wie man den Motiven für das Abonnement der Bistumszeitung entnehmen kann, spielt in unserer zwischenzeitlich stärker säkularisierten Welt, in der auch viele Pfarrer und Vertreter katholischer Laiengremien nicht oder zumindest nicht vorbehaltlos hinter der Kirchenzeitung stehen, solcher Meinungsklimadruck in aller Regel keine entscheidende Rolle mehr. Noch stärker als vor 20 Jahren ermittelt, hat sich der Abonnentenstamm der Kirchenzeitungen auf den engeren Kreis der älteren, überwiegend weiblichen Kirchentreuen reduziert, die in der Bistumszeitung vor allem Bestätigung im tradierten Glauben suchen. Diese verbliebenen Kernleser sind mit den bestehenden Angeboten der Kirchenzeitungen, mit den redaktionellen Inhalten wie auch mit Sprache und Layout in hohem Maße zufrieden.23

22 Schmolke, Michael: Kommentar zu wichtigen Ergebnissen der Feldbefragung. In: IfK (1975), a.a.O., Seite 4.

23 Auch bei den 1985 durchgeführten Resonanzanalysen bei Vorlage konkreter Kirchenzeitungsexemplare ließen sich aus den Urteilen der Abonnenten bzw. Hauptleser im Haushalt "keine gravierenden Schwachstellen" bei der Aufmachung und Gestaltung erkennen, und auch bei den redaktionellen Beiträgen stellten „die Leser ihren Kirchenzeitungen ein gutes Zeugnis aus". MMA (1986), a.a.O., Seite 13f. 
Angesichts der kontinuierlichen, noch immer ungebremsten Auflagen- und Reichweitenverluste der Kirchenzeitungen sind unterschiedliche Handlungsstrategien denkbar.

Erstens: Wenn immer weniger Katholiken bereit sind, Geld für eine Bistumszeitung auszugeben, würde es naheliegen, die Bistumszeitung als bezahlte Abonnementszeitung aufzugeben und statt dessen ein kostenloses Mitteilungsblatt der Kirche an alle katholischen Haushalte zu verteilen. Dieser Vorschlag wird von den dazu befragten Bischöfen und Verlegern entschieden abgelehnt (Tabelle 6), unter anderem, weil das, was nichts kostet, nach Uberzeugung vieler auch nichts wert sei, gleich in den Papierkorb wandern würde, und die Lage der Bistumszeitungen offensichtlich als noch nicht so hoffnungslos angesehen wird, als daß man zu dieser Alternative als letztem Mittel greifen muß.

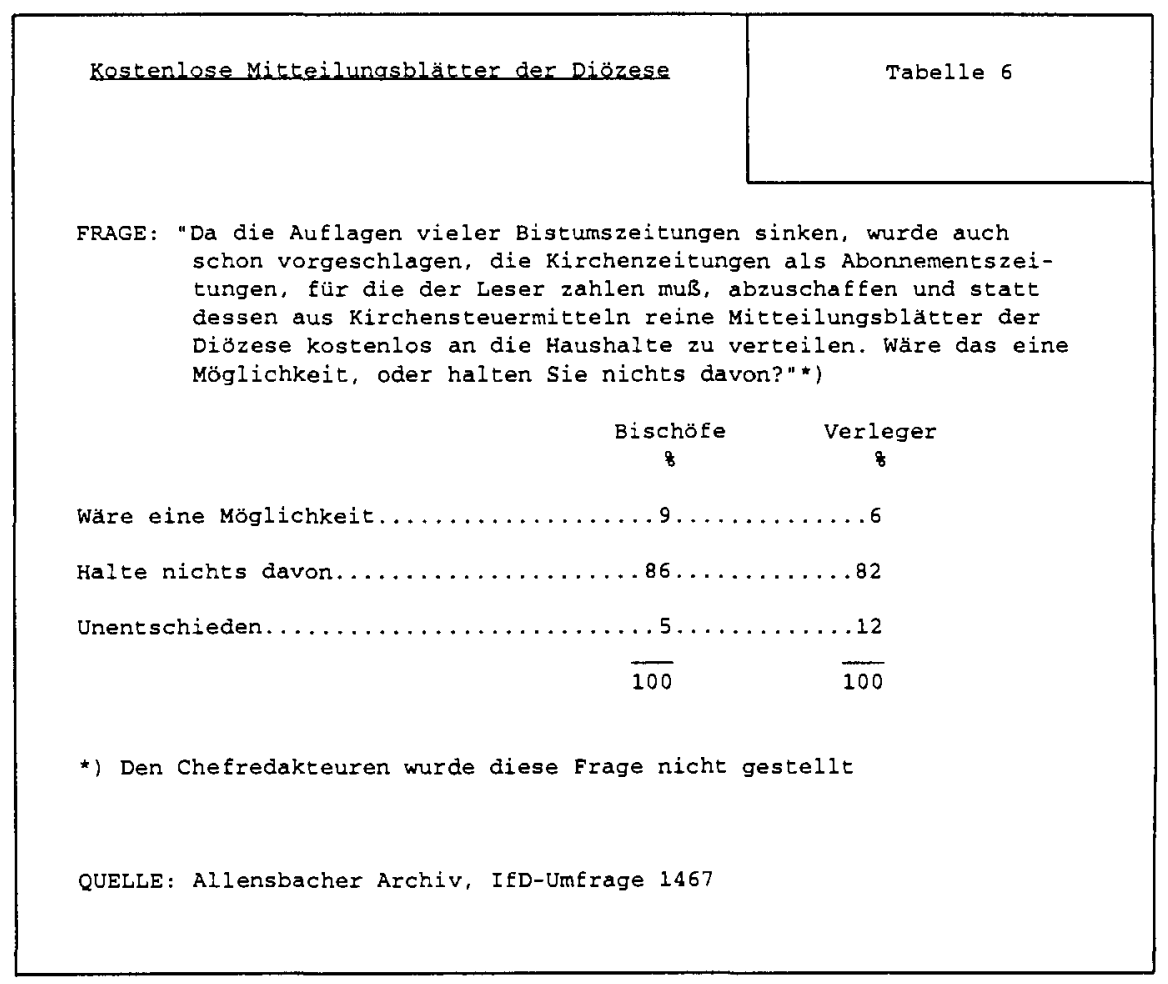

Zweitens: Ohne weitere Investitionen könnte man die Kirchenzeitung mit dem Wegsterben ihrer überalterten Leserschaft gleichsam langfristig ,auslaufen lassen'. Damit aber würde sich die Kirche eines wichtigen Kommunikationsmediums begeben, das noch immer für einen beachtlichen Teil ihrer Gläubigen Bedeutung hat und dessen Kernkonzept auch ein beträchtliches Interessentenpotential außerhalb der gewonnenen Leserschaft anspricht. 
Alles spricht deshalb dafür, einen dritten Weg zu gehen, die Kirchenzeitungen für die Kernleser zu optimieren und zugleich zu öffnen, insbesondere für die Leseinteressen der nachwachsenden Generation etwa ab 40jähriger Katholiken des Interessentenpotentials, die kirchennah geblieben sind oder sich zumindest für Werte- und Sinnfragen interessieren. Die Distanz der noch jüngeren Katholiken zur Gattung ,Bistumszeitung' als Medium der innerdiözesanen Kommunikation ist in der Regel zu groß, als daß man empfehlen könnte, z.B. schon 20- oder 30jährige als Hauptzielgruppe für die Akquisition neuer Abonnenten anzusehen. Daß man dennoch auch für die noch Jüngeren, insbesondere z.B. für junge Familien, Interessantes in der Kirchenzeitung anbieten muß, um zu signalisieren, daß man in der Zeit steht, für alle Altersgruppen offen ist und damit vielleicht auch den einen oder anderen Jüngeren als zumindest gelegentlichen Leser gewinnen kann, bleibt selbstverständlich.

In seinem Kommentar zur Feldbefragung von 1975 hat Michael Schmolke auf das "generelle thematische Dilemma der Redaktionen" hingewiesen, aus „pastoral-publizistischen Erwägungen für alle da sein" zu sollen, „ihr redaktionelles Angebot, jedenfalls im Hinblick auf die Zielgruppen Jugend und Alter, so gestalten zu müssen, daß die Alten bei der Stange bleiben, obwohl für die Jugend Dinge angeboten werden, die auf deren spezielle Interessen zugeschnitten sind, möglicherweise aber doch die Toleranz der Älteren strapazieren". ${ }^{24}$

Nach den Erkenntnissen aus der Situationsanalyse 1994 muß davor gewarnt werden, den ,Altersspagat' zu überreizen. Unterhalb der jetzigen ,Bezieher-Abbruchkante‘ gibt es eine, wie Schmolke ausführt, von den Redaktionen "vermutete und erhoffte ,Anknüpfungsschwelle" in der Altersskala"25, die aus heutiger Sicht zwischen 40 und 50 Jahren liegen dürfte. In dieser mittleren Lebensphase sind die Chancen, Katholiken mit den unverzichtbaren Kerninhalten eines Printmediums der Gattung ,Bistumszeitung' erfolgreich anzusprechen, ungleich größer als in den darunterliegenden Jahrgängen.

Im Gegensatz zu den als Abonnenten einer Bistumszeitung gewonnenen haben unter-45jährige Katholiken heute nicht nur zu ihrer Diözese, sondern vielfach auch zu ihrer eigenen Pfarrgemeinde nur eine schwache Bindung (Tabelle 7). Dies gilt auch für unter-45jährige, die zum Potential für eine kirchliche oder christliche Zeitung, Zeitschrift zählen. Dagegen ist die Bindung an das Bistum sowohl bei Katholiken, die sich als gläubiges Mitglied ihrer Kirche bezeichnen, als auch generell bei 45jährigen und älteren des Interessentenpotentials deutlich enger.

24 Schmolke, Michael: Kommentar zu wichtigen Ergebnissen der Feldbefragung. In: IfK (1975), a.a.O., S. 39. 
Katholiken, die zum Potential für eine kirchliche oder christliche Zeitung, Zeitschrift zählen

\begin{tabular}{|c|c|c|c|c|}
\hline $\begin{array}{c}\text { insge- } \\
\text { samt }\end{array}$ & $\begin{array}{c}\text { Unter- } \\
\text { 45jäh- } \\
\text { rige }\end{array}$ & $\begin{array}{l}\text { 45jährige } \\
\text { und alltere }\end{array}$ & $\begin{array}{c}\text { "Ich bin gläu- " } \\
\text { biges Mitglied } \\
\text { meiner Kirche a } \\
\text { und stehe zu } \\
\text { ihrer Lehre" } \\
\text { \% }\end{array}$ & $\begin{array}{l}\text { "Ich fühle mich } \\
\text { als Christ, } \\
\text { aber die Kirche } \\
\text { bedeutet mir } \\
\text { nicht viel“" } \\
\%\end{array}$ \\
\hline 72 & 53 & 79 & \begin{tabular}{|l|}
91 \\
\end{tabular} & 36 \\
\hline 28 & \begin{tabular}{|l|}
47 \\
\end{tabular} & 21 & 9 & 64 \\
\hline 44 & 25 & 52 & 63 & 14 \\
\hline 54 & 75 & 46 & 35 & 84 \\
\hline
\end{tabular}

Bindung an die Pfarrgemeinde

,eng' oder, mittel'

,nur ganz lose' bzw.

'gar keine Bindung

Bindung an das Bistum

,eng' oder, mittel'

„nur ganz lose' bzw.

'gar keine Bindung'

Das Interesse der 45jährigen und älteren, die zum Interessentenpotential zählen, sowohl an Stellungnahmen und Aussagen des Papstes und der Bischöfe, an Berichten aus dem Leben der Kirche als auch aus dem Bistum ist sehr viel größer als das Interesse der jüngeren Katholiken daran.

Katholiken, die zum Potential für eine kirchliche oder christliche Zeitung, Zeitschrift zählen

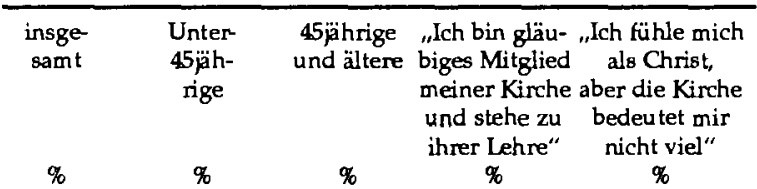

Es interessieren sich für

Stellungnahmen und

Aussagen des Papstes

und der Bischöfe

48

32

54

57

40

Berichte über kirch-

liche Ereignisse und

Entwicklungen aus

aller Welt

48

27

57

64

23

Bistums

27

11

33

40

8

(Quelle: Allensbacher Archiv, IfD-Umfrage 6010) 
FRAGEN: "Wie würden Sie Ihre persönliche Bindung an Ihre Pfarrgemeinde beschreiben? Würden sie sagen ..."

"Wie würder. Sie Ihre persönliche Bindung an Ihr, Bistum beschreiben? Würden sie sagen ..."

\begin{tabular}{|c|c|c|c|c|c|}
\hline & & Katholik & 3 & & $2: 17$ vez- \\
\hline $\begin{array}{l}\text { insge- } \\
\text { sant }\end{array}$ & $\begin{array}{l}\text { 16 - } 29- \\
\text { jahrige }\end{array}$ & $\begin{array}{l}30-44- \\
j a t=i g e\end{array}$ & $\begin{array}{l}45-59- \\
j a x=g e\end{array}$ & $\begin{array}{l}60 j a n r i g e \\
\text { L. a:zere }\end{array}$ & $\begin{array}{l}\text { Aborrea- } \\
\text { Len eiter }\end{array}$ \\
\hline & & & & & $\begin{array}{c}\mathrm{Ki}=\text { cherze: } \\
\mathrm{turg}\end{array}$ \\
\hline 8 & 8 & 8 & 8 & $\frac{7}{3}$ & 3 \\
\hline
\end{tabular}

\section{Bindung an die Pfarrgemeinde}

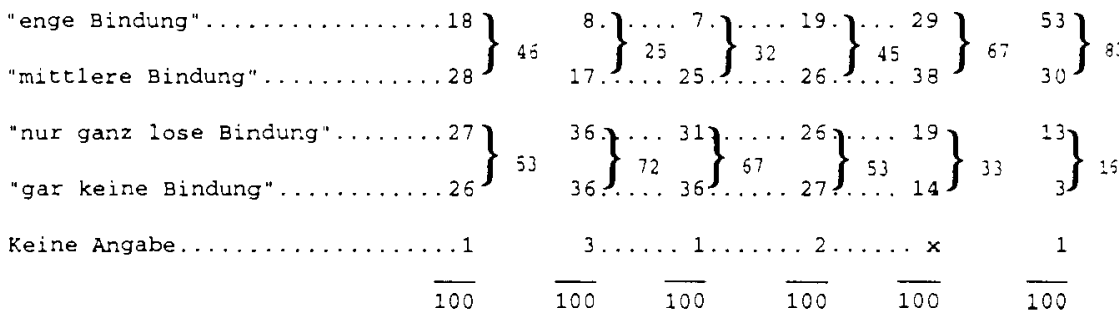

Bindung an das Bistun

"enge Bindung“.

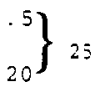

\}$\left._{9}^{3} \ldots{ }_{10}^{2}\right\}$

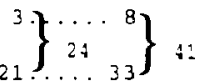

${ }_{39}^{27} 6=$

"gur ganz lose Bindung".....27

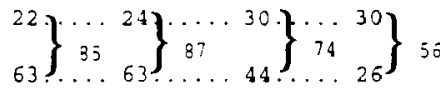

\}$_{9}^{23} 32$

Keine Angabe.

$\ldots 2$

$3 \ldots \ldots 2 \ldots \ldots 2 \ldots 3$

2

$\overline{100}$

$$
\overline{100}
$$$$
\overline{100}
$$$$
\overline{100}
$$

QUELLE: Allensbacher Archiv, IsJ-Umazagen 6013 (Uasuar 1995) und 1457 (Sommer 1994) 
Dies gilt auch für Glaubenshilfen, die sich nicht in bloßer Verkündigung erschöpfen, sondern Antworten auf existentielle Fragen geben, z.B. was Glauben in der heutigen Zeit bedeutet.

Katholiken, die zum Potential für eine kirchliche oder christliche Zeitung, Zeitschrift zählen

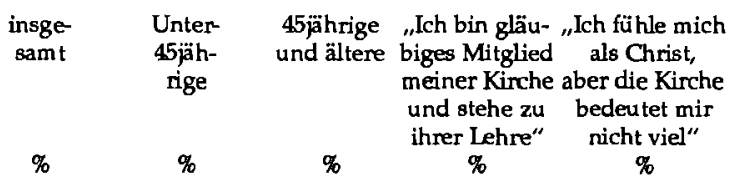

Es interessieren sich für -

Welche Bedeutung die

Kirche in unserer

Gesellschaft hat

Was Glauben in unserer

heutigen Zeit bedeutet

$\begin{array}{lllll}55 & 37 & 61 & 69 & 30 \\ 52 & 36 & 59 & 67 & 22\end{array}$

Unter-45jährige und katholische Christen, die sich von der Kirche entfernt haben, aber dennoch zum Interessentenpotential für eine kirchliche oder christliche Zeitung, Zeitschrift zählen, sind zwar nicht an Berichten aus dem Leben des Bistums, nicht z.B. an mehreren Seiten Personalia auch aus entfernten Ecken des Bistums interessiert, wohl aber an Stellungnahmen und Kommentaren der Kirche zu den Problemen unserer Zeit, an Sinnfragen und Lebenshilfe (Tabelle 8).

Die von Ferdinand Oertel in seinem Kommentar zur Feldbefragung von 1975 gestellte "Grundfrage: Ob die Kirchenpresse verstärkt die jüngere und mittlere Generation ansprechen soll, ohne dadurch höhere Abbestellungen unter den Älteren zu bewirken, oder ob sie sich auf ihre Hauptleser im vorgerückten Alter stützen kann, während eine gezielte Ansprache der Jugend publizistisch (und pastoral) anderweitig erfolgen muß ${ }^{\prime 26}$, ist nach den Erkenntnissen aus der Potentialbefragung von 1995 erfolgversprechender zugunsten der letzteren Alternative zu beantworten - zumindest solange die Kirchenzeitung den Auftrag hat, primär Medium der diözesanen Kommunikation zu sein. Am kirchlichen Leben des Bistums nicht, dagegen an Stellungnahmen der Kirche zu aktuellen Fragen, Wertediskussion, Orientierungs- und Lebenshilfe stark interessierte junge Katholiken und Sinnsuchende wird man eher z.B. mit kirchlichen Zeitschriftenangeboten für junge Zielgruppen erreichen als mit dem Bistumsblatt.

Auch Bischöfe und Verleger tendieren heute mehrheitlich zu der Ansicht, langfristig sei es erfolgversprechender, wenn sich die Bistumszeitung auf wichtige Zielgruppen konzentriere, anstatt $\mathrm{zu}$ versuchen, mit einem immer breiteren inhaltlichen Angebot neue Leser zu gewinnen. Die Chefredakteure sind in dieser Frage geteilter Meinung bzw. unentschieden (Tabelle 9).

26 Oertel, Ferdinand: Informationsverhalten und -erwartungen der Katholiken. In: IfK (1976), a.a.O., Seite XXXIV. 
Katholiken, die zum potential für eine kirchliche oder christliche zeitung, Zeitschrift zählen -

\begin{tabular}{|c|c|c|c|c|}
\hline $\begin{array}{c}\text { insge- } \\
\text { samt }\end{array}$ & $\begin{array}{l}\text { Unter- } \\
45 j a ̈ h- \\
\text { rige }\end{array}$ & $\begin{array}{l}45 j a \text { h - } \\
\text { rige und } \\
\text { altere }\end{array}$ & $\begin{array}{c}\text { "Ich bin glau- } \\
\text { biges Mitglied } \\
\text { meiner Rir- } \\
\text { che und stehe }\end{array}$ & $\begin{array}{l}\text { "Ich Eühle } \\
\text { mich als } \\
\text { Christ,aber } \\
\text { die Kirche }\end{array}$ \\
\hline & & & $\begin{array}{l}\text { zu ihrer } \\
\text { Lehre" }\end{array}$ & $\begin{array}{l}\text { bedeutet mir } \\
\text { nicht viel" }\end{array}$ \\
\hline 8 & 8 & 8 & 8 & 8 \\
\hline
\end{tabular}

Es interessieren sich für -

Stellungnahmen, Kommentare $\mathrm{zu}$

den Problemen unserer Zeit... 63

Uber den Sinn des Lebens..... 58

73. ... 59

$66 . \ldots 55$

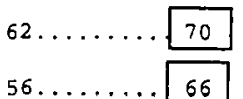

Wie man mit Lebenskrisen um-

gehen kann. ........... 57

Positiv denken lernen.

.47

59

... 56

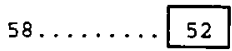

$65 . \ldots 40$

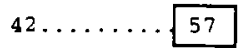

Lebenshilfe, wie man im Leben

besser zurechtkommt........46 46

$43 \ldots .47$

$55 \ldots \ldots 31$

Wie man den Kindern den Glau-

ben nahebringen kann....... 44

Fragen der okumene, der zusam-

menarbeit zwischen den christ-

1ichen kirchen........... 39

Ratschlage für Ehe und Familie 32

$32 \ldots .42$

$43 \ldots \ldots+33$

$46 \ldots 26$

$31 \ldots \ldots \ldots 40$

Ratschlage zur Kinder-

erziehung.

$54 \ldots 24$

QUELLE: Allensbacher Archiv, IfD-Umfrage 6010 


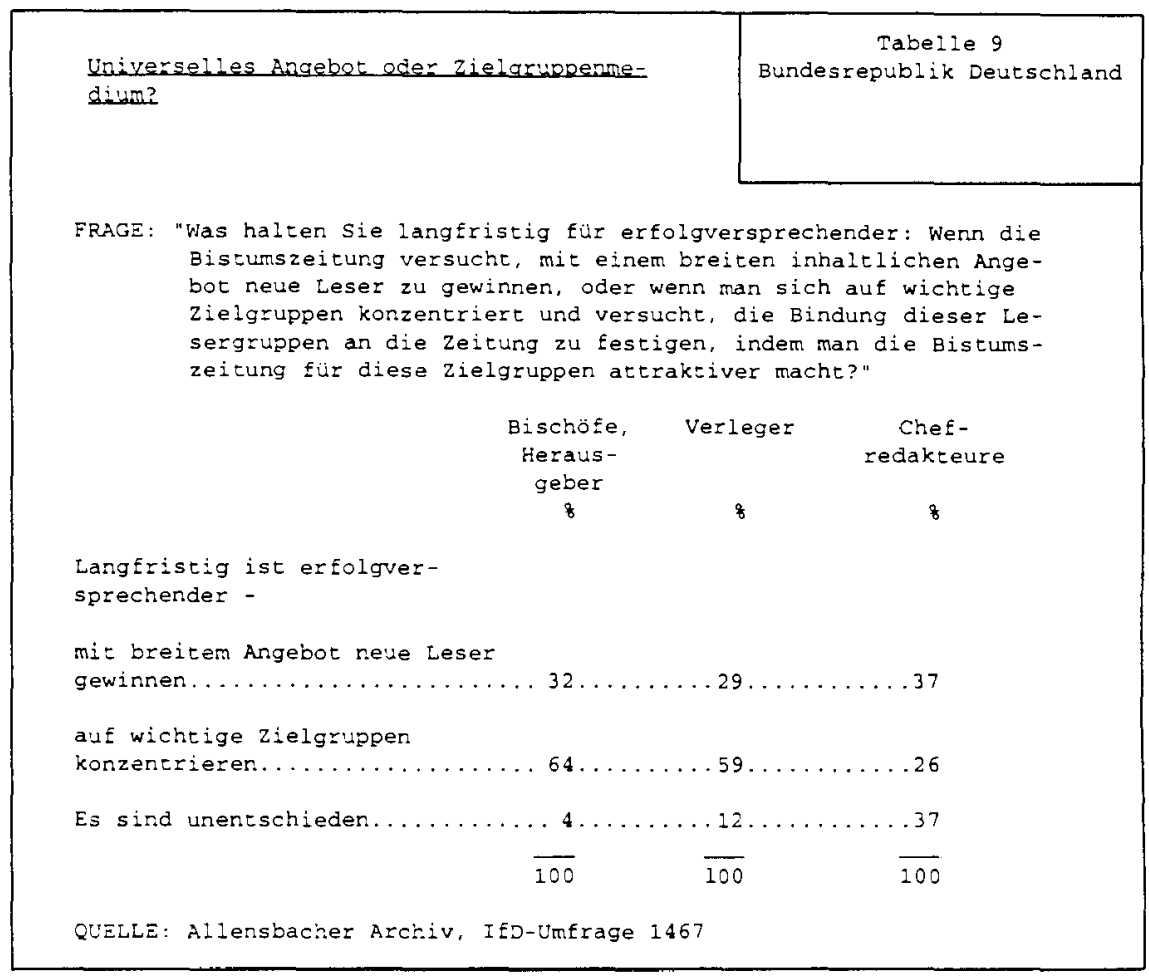

Konzentration auf wichtige Zielgruppen heißt nach den Erkenntnissen aus dieser Studie in den Kirchenzeitungen einen begrenzten Spagat zu wagen, die Wünsche, Bedürfnisse der meist älteren Kernleser und zugleich der nachwachsenden etwa ab 40jährigen Katholikengeneration des an Kirche, Glaubens- und Sinnfragen interessierten Potentials zu erfüllen. Die Erwartungen dieser beiden Zielgruppen sind nicht $\mathrm{zu}$ heterogen, auch sollte die geistige Flexibilität und Lernfähigkeit der heute Älteren nicht unterschätzt werden.

Wenn der Altersspagat gelingen soll - Konzessionen an die Interessen, Wünsche und Erwartungen der ab 40jährigen Katholiken, die zum Potential zählen, ohne die Akzeptanz der überwiegend 60jährigen oder älteren Kernleser zu gefährden -, müssen die redaktionellen Angebote sorgfältig geprüft werden.

"Weil es mir wichtig ist zu wissen, wie die Kirche zu bestimmten

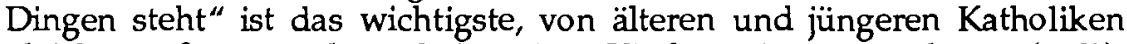
gleichermaßen geteilte Motiv, eine Kirchenzeitung zu lesen (66\%), gefolgt von dem. Motiv, "weil man dort Informationen bekommt, die man woanders nicht findet" $(58 \%)$.

Wenn sich die Bistumszeitungen im sich ständig verschärfenden Medienwettbewerb behaupten wollen, müssen sie sich von anderen 
Medien, wie z.B. Tageszeitungen, Zeitschriften, Fernsehen oder Hörfunk abheben durch exklusiven Zusatznutzen, den keines der anderen kirchlichen oder säkularen Medien auf vergleichbare Weise vermittelt. Auch Radio und Fernsehen berichten über wichtige Ereignisse in der Kirche, vor allem der Weltkirche und auf nationaler Ebene, regionale Tageszeitungen informieren darüber hinaus auch über kirchliche Ereignisse in Pfarrgemeinde und Dekanat. Pfarrbriefe und oft auch das Mitteilungsblatt der politischen Gemeinde bringen vieles, was zur Information über die Pfarrgemeinde wichtig ist. Informationen auf Diözesanebene, z.B. aus dem Leben des Bistums' einschließlich der Personalia im Bistum, reichen als exklusiver Zusatznutzen nicht aus, um das Überleben der Mediengattung 'Bistumszeitungen' zu sichern. Stellungnahmen und Aussagen des eigenen Bischofs finden in vielen Bistümern großes Interesse, weniger dagegen die vielen Nachrichten und Berichte aus anderen, entfernteren Dekanaten und Gemeinden der Diözese, mit denen viele Bistumszeitungen in Wahrnehmung einer extensiv verstandenen Chronistenpflicht viele ihrer Seiten füllen. Insbesondere Katholiken aus dem psychologischen Interessentenpotential interessieren sich dafür nicht. Konzentration auf Exemplarisches aus dem Bistum ist sicher besser als der ohnehin zum Scheitern verurteilte Versuch, möglichst von allem etwas zu bringen.

Die eigene Kirchengemeinde und auch noch das eigene Dekanat sind die unmittelbaren Identifikations- und Interessenebenen vieler Leser. Darüber mehr zu berichten, z.B. auf lokalen oder regionalen Wechselseiten, würde das Interesse an der Kirchenzeitung ohne Zweifel stärken.

Vertiefende Hintergrundberichterstattung über kirchliche Ereignisse, die den Lesern der Kirchenzeitung in der Regel schon aus tagesaktuellen Meldungen anderer Medien bekannt geworden sind, sowie Stellungnahmen und Kommentare zu wichtigen Problemen unserer Zeit aus kirchlicher, christlicher Sicht müßten als exklusiver Zusatznutzen der Kirchenzeitungen stärker profiliert werden. Stellungnahmen der Kirche, z.B. zum Umbau des Sozialstaates, zur Fremdenfeindlichkeit in Deutschland oder zum Schutz des ungeborenen Lebens, sind dafür hervorragende Beispiele.

Vor allem jüngere und besser gebildete Katholiken legen auf eine Stärkung der Forumsfunktion, auf eine Förderung des offenen Dialogs zwischen unterschiedlichen Positionen innerhalb der Kirche großen Wert. In der Kirchenzeitung muß deshalb auch Raum sein für kontrovers diskutierte Themen wie z.B. ,Pflichtzölibat' oder ,Frauenordination'. Aber die Wahrnehmung der Forumsfunktion darf nicht zu Beliebigkeit führen, die unterschiedlichen Positionen dürfen nicht unvermittelt nebeneinanderstehen. Vielmehr ist auch hier entschiedene Stellungnahme als Orientierungshilfe dringend erwünscht.

Der zentrale pastorale Auftrag der Kirchenzeitungen darf sich 
nicht in bloßer Glaubensverkündigung erschöpfen. Wichtig ist es, in der Kirchenzeitung die Bedeutung des Glaubens für die Menschen in unserer Zeit zu erschließen. Viele im Glauben Verunsicherte suchen nach Orientierungshilfen, z.B. wie man , mit Glaubenskrisen umgehen kann'. Auch Mittel und Wege, ,den Kindern den Glauben nahezubringen', sind eine wichtige Erwartung vieler Katholiken an die Kirchenzeitung.

Antworten auf ,Fragen nach dem Sinn des Lebens' oder ,Wie man mit Lebenskrisen umgehen kann' zählen zu den wichtigsten Themeninteressen der Katholiken, die zum bisher unerschlossenen Leserpotential zählen. Antworten auf Sinnfragen, aber auch konkrete Lebenshilfen geben, z.B. bei zwischenmenschlichen Problemen, sind deshalb weitere wichtige Aufgaben der Kirchenpresse, die - lebensnah, kompetent und glaubwürdig erfüllt - die Leser-Blatt-Bindung der gewonnenen Abonnenten stärken und gute Chancen eröffnen, Katholiken aus dem psychologischen Interessentenpotential als neue Leser zu gewinnen.

Ratgeber und Serviceangebote, wie Fernseh- und Hörfunktips, -kritiken und -empfehlungen aus kirchlicher Sicht bis hin zu Gesundheitstips oder ,Tips für Haus und Garten', sind wichtige Zusatzangebote, die die Leser-Blatt-Bindung bestimmter Lesersegmente erhöhen.

Auch Unterhaltungsbeiträge wie Humor, Rätsel, Erzählungen, Fortsetzungsromane sind für viele Leser wichtige Bindungselemente. Sie bieten in besonderem Maße Chancen, Lesefreude zu vermitteln. Aber auch in allen anderen Teilen müssen sich die Kirchenzeitungen um eine positivere Ausstrahlung bemühen. Dazu zählt auch, Kirche und Glauben im Blatt offensiver zu vertreten, den Lesern mehr Mut und Hoffnung zu geben.

Auch wenn Veränderungen der Inhalte, thematische Öffnungen und Umgewichtungen letztlich wichtiger sind als die Form, müssen sich die Kirchenzeitungen um ein zeitgemäßes, den Leser ansprechendes, interessantes, lebendiges Layout, um klare Gliederung, um gute ,optische Leserführung' zur leichteren Orientierung im Blatt bemühen. Die Kirchenzeitungen müssen leicht verständlich geschrieben, angenehm zu lesen sein, auch Lesespaß vermitteln. Von einem bloß ,optischen Faceliftung' oder ,flotteren Schreibstil' allein wird man allerdings keine Auflagenzuwächse erwarten können.

Die Situationsanalyse 1994 zeigt, daß auch unter den Kommunikatoren weitgehend Konsens über die zu treffenden Maßnahmen besteht. Wo sich Dissens abzeichnet, z.B. bei der Gewichtung von innerkirchlicher Kritik, von Unterhaltungsbeiträgen, Ratgeber- und Serviceleistungen, bieten die Erkenntnisse aus dieser Studie eine fundierte Basis für Verständigungsgespräche. 
b) Plädoyer für ein publizistisches Gesamtkonzept, das sowohl kirchliche als auch säkulare Medien einschließt

In seinem Referat ,Zielgruppenspezifisch veröffentlichen. Zielgruppen, Prioritäten und Marktorientierung' hat sich Hans-Josef Joest 1989 für eine stärker zielgruppenspezifische Pressearbeit der katholischen Kirche eingesetzt und dabei neben neuen Angeboten für junge Katholiken, junge Familien, auch eine neue Zeitschrift für ,Sonntagschristen' und ,Sinnsuchende' gefordert, die sich „mit Glaubensfragen im Alltag auseinandersetzt “. Darin sollten „Antworten des Neuen Testaments und Zeugnisse praktizierender Christen" im Vordergrund stehen, "Verlautbarungen der Amtskirche dagegen zurücktreten “.27

Die hier gefundene Bistums- und zum Teil auch Kirchenferne der jüngeren Katholiken des Interessentenpotentials macht es unwahrscheinlich, durch eine Optimierung der bestehenden Gattung ,Bistumszeitung für die Kernleser und die $a b$ etwa 45jährigen des Interessentenpotentials allein die wichtigen jüngeren Potentiale ausschöpfen zu können. Vielmehr müssen im Rahmen eines publizistischen Gesamtkonzepts auch die Eignung der bestehenden Special-InterestAngebote der Kirchenpresse, von Kirchenfunk, kirchlichen TV-Sendungen und auch katholischen Buchverlagen bis hin zu den Pfarrbriefen in den Gemeinden überprüft und gegebenenfalls parallel zur Optimierung der bestehenden Angebote neue Angebote für die Zielgruppe der jüngeren, nicht mehr kirchennahen, Sonntagschristen' und ,Sinnsuchenden' entwickelt werden. Aufgrund der Distanz eines Teils dieses Potentials zu explizit kirchlichen Angeboten müssen auch alle Möglichkeiten für verstärkte redaktionelle Kooperationen der Kirche mit säkularen Medien, z.B. Hörfunk, Fernsehen, Zeitungen und Zeitschriften geprüft werden. Für lokale und regionale kirchliche Informationen können auch die Lokalzeitungen sowie Amtsblätter der politischen Gemeinden gut geeignete Kooperationspartner sein.

Während sehr viele Bischöfe, Verleger und alle befragten Chefredakteure von Kirchenzeitungen Chancen sehen, durch Glaubensunsicherheit charakterisierte ,Sonntagschristen' mit der Bistumszeitung zu erreichen, werden diese Chancen bei ,Sinnsuchenden', "die Christsein als mögliche Antwort auf existentielle Fragen ansehen, aber meist keine Bindung mehr an die Kirche als Institution haben"28, weitaus skeptischer gesehen. Vor allem Verleger von Kirchenzeitungen

27 In: Sekretariat der Deutschen Bischofskonferenz (Hrsg.): Katholische Presse. Kolloquium der Publizistischen Kommission der Deutschen Bischofskonferenz 10./11. Oktober 1989. Referate und Diskussionen. Arbeitshilfen, Heft 79, Dezember 1989; Seite 67f.

28 Die Termini Sonntagschristen' und Sinnsuchende' wurden in dieser Weise von Hans-Josef Joest definiert. Vgl. dazu Joest, Hans-Josef: Zielgruppenspezifisch veröffentlichen. Zielgruppen, Prioritäten und Marktorientierung. In: Katholische Presse, a.a.O., S. 70. 
halten für diese Zielgruppe kirchlicher Publizistik Hörfunk und Fernsehen für geeigneter (Tabelle 10).

Die befragten Bischöfe wie die Verleger vertraten nahezu einmütig die Auffassung, daß die Position und Funktion der Bistumspresse im Rahmen einer publizistischen Gesamtkonzeption neu definiert werden muß; in vielen Diözesen werden solche Neukonzeptionen zur Zeit diskutiert oder entwickelt.

FRAGE: "Halten Sie es für notwendig, daß im Bistum ein klares publizistisches Konzept für die Presse und Offentlichkeit entwickelt wird, das auch die Stellung und die Funktion der Bistumszeitung klar umreißt, oder halten Sie das nicht für erforderlich?"

\begin{tabular}{|c|c|c|c|}
\hline & $\begin{array}{c}\text { Bischöfe, } \\
\text { Heraus- } \\
\text { geber } \\
\%\end{array}$ & Verleger & $\begin{array}{c}\text { Chef- } \\
\text { redakteure } \\
\%\end{array}$ \\
\hline Halte ich für notwendig & g 91 & 82 & 53 \\
\hline gibt es bereits & 14 & 17 & 5 \\
\hline ist in Arbeit & 45 & 29 & $x$ \\
\hline noch nicht in Arbeit & 32 & 35 & 47 \\
\hline Nicht erforderlich & 9 & 18 & 31 \\
\hline Unentschieden & $\mathrm{x}$ & $x$ & 16 \\
\hline & 100 & 100 & 100 \\
\hline
\end{tabular}

(Quelle: Allensbacher Archiv, IfD-Umfrage 1467)

\section{c) Stärkere überdiözesane Kooperation}

Schon in den 1972 von der Arbeitsgemeinschaft Katholische Presse (AKP) verabschiedeten ,Grundsätzen für einen Rahmenplan der Kirchenpresse' wurde die Bildung einer Gemeinschaftsredaktion vorgeschlagen. Überdiözesane Lösungen wurden jedoch - wie Ferdinand Oertel in seiner kritischen Bilanz der letzten 20 Jahre ausführt behindert, nicht zuletzt aufgrund von Furcht vor einer ,Einheitskirchenzeitung' sowie infolge "Erbhofdenkens“ (Michael Schmolke), „schwer oder praktisch gar nicht zu ändernden Besitzverhältnissen, Herausgeber- und Verlagskonstruktionen und anderen traditionellen Gegebenheiten und Gewohnheiten. ${ }^{29}$

Angesichts sinkender Kirchensteuereinnahmen auf der einen und

29 Oertel, Ferdinand: Die Krise der Bistumspresse 1989. Bestandsaufnahme und Überlegungen. In: Communicatio Socialis, Heft 1-2 1989, S. 36. 
Chancen eher bei Sonntagschrister. kain bei_sinsuchender
Tabelie 10

Bundesrepublik Deuzschland

\section{Bischöfe,}

Fierausgeber

के

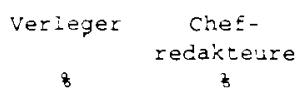

Es sehen chancen, mit

der Kirchenzeitung anzu-

sprechen -

Sonntagschristen, die durch

Glaubensunsicherheit gekenn-

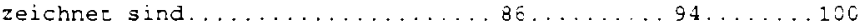

Sinnsuchende, die christsein a:s

mögliche Antwort aut existe:-

tielle Fragen ansehen, aber meis:

keine Bindung mehr an die Kircine

als Institution haben.

Für Sinnsuchende gibt

es geeignetere Medien.........59......77 ..... 37

und zwat u.a.:

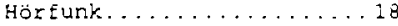

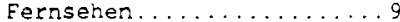

zeitungen, zeit-

schriften..............19

Special-Interest-

titel fur religiöse

Interessen..............

Bücher................ 
wachsenden Subventionsbedarfs der Bistumszeitungen auf der anderen Seite gewinnt die von Hermann Glandorf beim Kolloquium ,Katholische Presse' 1989 vor allem aus ökonomischen Erwägungen geforderte Verstärkung der Kooperation zwischen den verschiedenen Kirchenzeitungsverlagen stärkeres Interesse. ${ }^{30}$

Die Erkenntnisse aus der Situationsanalyse 1994 stützen diese Forderung nachhaltig, und zwar zum einen durch die hier ermittelte

- überraschend geringe Bedeutung des Bistums als Identifikationsund Interessenebene für viele Katholiken

zum anderen durch die

- gleich große Zufriedenheit der Abonnenten von Kirchenzeitungen aus Kooperationen (NO-Kooperation und Knecht-Kooperation) sowohl mit der Glaubensverkündigung, der Hintergrundberichterstattung aus dem kirchlichen Leben, der Kommentierung aus christlicher Sicht als auch mit der Berichterstattung über die eigene Pfarrgemeinde. Selbst bei der Forderung ,Stärkung der Gemeinschaft innerhalb der Diözese' wird von den Lesern der Kooperationszeitungen in ihrer Kirchenzeitung kein größeres Defizit erlebt als von den Abonnenten von Kirchenzeitungen, die als exklusives Angebot eines Bistums erscheinen.

Auf ihre Kinchenzeitung trifft zu

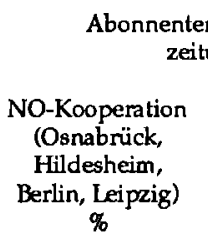

Nimmt zu aktuellen Problemen aus christlicher Sicht Stellung Enthält viele Hintergrundberichte aus dem kirchlichen Leben Dient der Verkündigung des Glaubens

Berichtet häufig über die Pfarngemeinden vor Ort

Stärkt die Gemeinschaft innerhalb der Diözese
72

56

65

46

43
Abonnenten einer Bistumezeitung aus einem Kooperation Einzelverlag (Mainz, Fulda, Limburg)

$\%$

$\%$

68

53

65

43

44

Viele Verleger und Bischöfe beurteilen heute verstärkte Kooperationen positiv. Während Chefredakteure hier zurückhaltender sind, eher an fallweise Verabredungen zu redaktioneller Zusammenarbeit, z.B. bei bestimmten Themen, Beilagen, Supplements, denken, befürworten Bischöfe und Verleger mehrheitlich nicht nur verstärkte Kooperationen

30 Siehe dazu Glandorf, Hermann: Verlegerische Kooperation. In: Katholische Presse (1989), a.a.O., S. 41 f. 
im technischen Bereich bei der Zeitungsherstellung, beim Druck sowie Kooperationen beim Anzeigenverkauf, sondern auch die Gestaltung gemeinsamer überregionaler Hauptteile für mehrere Bistumszeitungen.

Der Vorschlag, überregionale qualifizierte Zeitungsteile zu produzieren und einen verbesserten bistumsbezogenen Teil einzubinden, ist heute für viele, wenn auch längst noch nicht alle überzeugend (Tabelle $11)$.

Die hier ermittelte größere oder zumindest gleich große Zufriedenheit der Abonnenten von Kirchenzeitungen aus VerlagsKooperationen, selbst mit der Diözesan- und Gemeindeberichterstattung, ist ein gewichtiges Argument, überdiözesane Kooperationen zu verstärken durch die Einrichtung weiterer Zentralredaktionen für große, vor allem auch mentalitätsmäßig ähnliche Regionen.

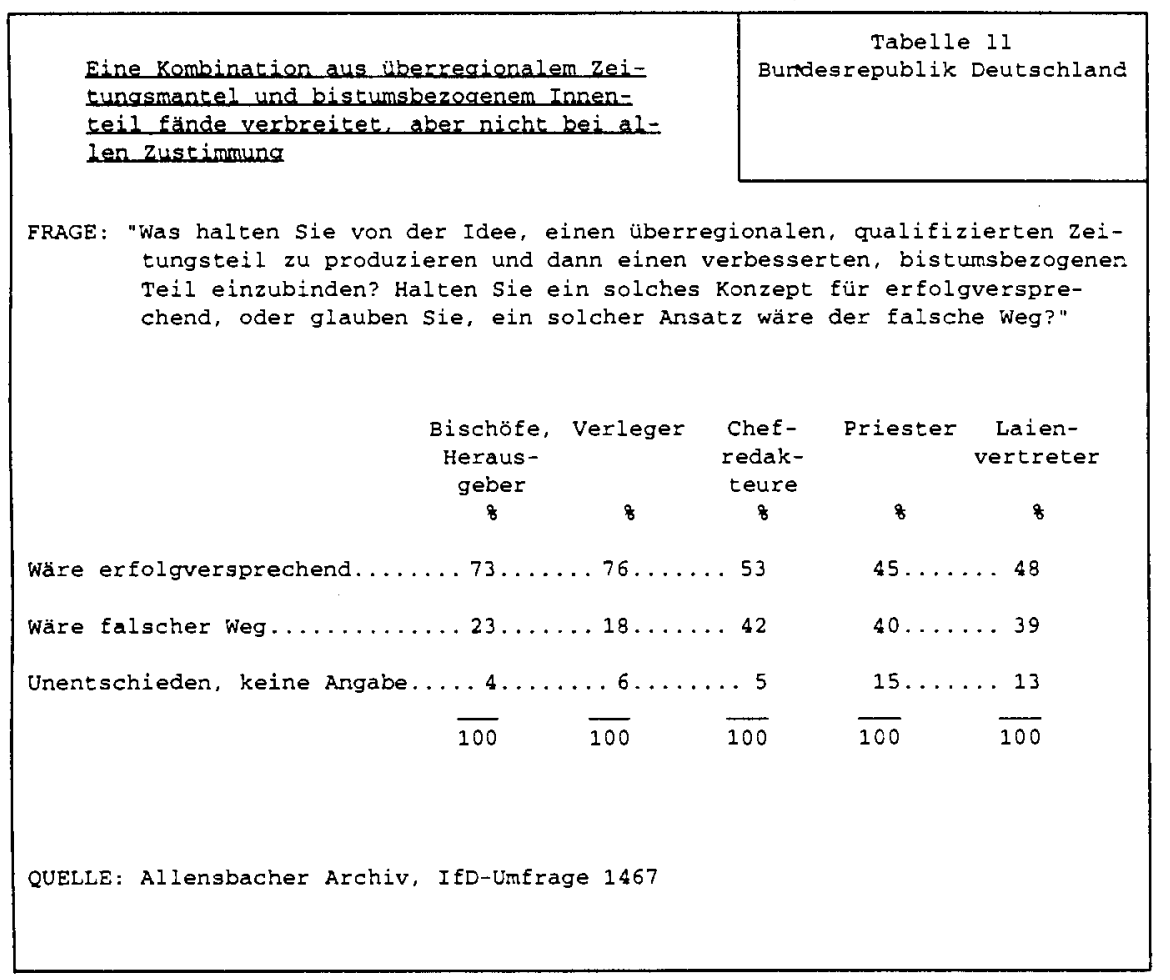

\section{d) Glaubwürdige Werbung}

Die Befragung der Vertriebs- bzw. Werbeleiter und die Analyse der Wege, wie die Abonnenten zum Abonnement der Bistumszeitung gekommen sind, haben gezeigt, daß man immer weniger auf eine 
Tradierung des Abonnements, den ungebrochenen Weiterbezug in der nachfolgenden Generation, bauen kann. Im immer schärferen Wettbewerb mit immer vielfältigeren, attraktiven säkularen Medienangeboten muß sich die Kirchenzeitung über exklusiven Zusatznutzen, wie kirchliche Informationen, Stellungnahmen und Orientierungshilfen aus kirchlicher, christlicher Sicht, die man sonst nirgendwo findet, selbst verkaufen.

Für die Neuakquisition von Abonnenten wird die Anwerbung über persönliche Überzeugungsversuche an der Haustür, am Informationsstand, der ,Königsweg' bleiben. ${ }^{31}$ Allerdings mit qualifizierteren, besser geschulten und vertrauenswürdigeren Werbern. Dabei könnten Empfehlungsschreiben des Bischofs und des Pfarrers vor Ort eine wesentliche Akquisitionshilfe sein. Bisher wurden nach eigener Aussage nur wenige Pfarrer vom Bischof oder Generalvikar gebeten, sich für die Verbreitung der Kirchenzeitung einzusetzen, auch von den Kirchenzeitungsverlagen zu wenige. Viele Pfarrer halten die Lektüre der Kirchenzeitung zwar ganz allgemein für wünschenswert, aber weder für ,wichtig' noch zur Information über ,Kirche und Glaube' notwendig. Die Verbreitung der Kirchenzeitung zu fördern, ist vielen Pfarrern bisher kein Anliegen, für das man sich besonders engagieren sollte. Nur $8 \%$ der befragten Priester haben nach eigener Aussage andere schon ,häufig' auf die Kirchenzeitung hingewiesen, etwas mehr zumindest 'gelegentlich". Nicht ohne Grund befürchtete Vorbehalte der Priester gegenüber dem bisherigen Angebot der Bistumszeitungen haben die dringend erforderliche Kommunikation mit Priestern und Laienvertretern über die Kirchenzeitung offensichtlich in vielen Diözesen ,blockiert'. Nur wenn es gelingt, die Priester in den Gemeinden vom Nutzen der Kirchenzeitung zu überzeugen und zu aktiver Empfehlung zu motivieren, wird man auch katholische Laien mit glaubwürdigen Argumenten vom Wert eines Abonnements der Bistumszeitung überzeugen können.

Zur Vorbereitung des Kolloquiums ,Katholische Presse' hatten 198919 Bischöfe bzw. ihre Beauftragten zur Frage "Ist die Bistumspresse für Ihr Bistum unverzichtbar?" schriftlich Stellung genommen. Werner Radspieler resümierte damals: „Einmütig ist das Urteil über die Unverzichtbarkeit der Bistumspresse und ihre redaktionelle und möglichst auch verlegerische Selbständigkeit im diözesanen Bereich".32 Auch 1994

31 Massenmediale Werbung, wie z.B. Plakate, Anzeigen in Gemeindebriefen, Hörfunkspots, Schreiben an alle katholischen Haushalte (Direct Mail) oder auch gezielte Briefe an Neuzugezogene oder z.B. Brautpaare können wichtige flankierende Maßnahmen sein, auf die Angebote der Kirchenzeitung aufmerksam zu machen. Allein allerdings dürften sie als Werbeimpuls zu schwach sein, nicht ausreichend motivieren, die Bistumszeitung zu abonnieren.

32 Katholische Presse (1989), a.a.O., S. 27 
sprechen sich die befragten Bischöfe mit großer Mehrheit für den Erhalt der Bistumszeitungen aus, aber offensichtlich sind angesichts des wachsenden Subventionsbedarfs und sinkender Kirchensteuereinnahmen nicht mehr alle Bischöfe für den Erhalt um jeden Preis. Zwei Drittel der in die Untersuchung einbezogenen Bistumszeitungen erhalten regelmäßig (55\%) oder zumindest gelegentlich für bestimmte Aufgaben (14\%) Zuschüsse des Bistums. Danach gefragt: "Gibt es für Sie bei der Auflage der Bistumszeitung eine Untergrenze, bei der Sie sagen würden, wenn die unterschritten ist, dann lohnt sich die Herausgabe einer Bistumszeitung nicht mehr?" gibt jeder dritte Bischof zu erkennen, daß er so eine Mindestauflage sieht. Die Mehrheit der Bischöfe will sich nicht auf eine bestimmte Untergrenze festlegen, vielmehr große Anstrengungen unternehmen, damit es erst gar nicht so weit kommt.

Nach Vorlage der Erkenntnisse aus der vergleichenden Situationsanalyse der deutschen Bistumszeitungen sind die dafür verantwortlichen Herausgeber, Verleger und Redaktionen aufgefordert, im Rahmen eines publizistischen Gesamtkonzepts festzulegen, welche Aufgaben die Bistumszeitung in Zukunft erfüllen soll und wie sie diese Aufgaben arbeitsteilig mit anderen Medien am besten erfüllen kann. Nur wenn das gemeinsam als richtig Erkannte anschließend von allen daran Beteiligten mit Entschiedenheit umgesetzt wird, kann es gelingen, alle Chancen zu nutzen, die sich den Kirchenzeitungen auch heute bieten.

\section{SUMMARY: Chances for diocesan weeklies}

The continual decline in circulation and the aging readership of diocesan newspapers are clear indications that this media genre is experiencing an existential crisis in Germany. The Allensbach Institute was thus commissioned by the Medien-Dienstleistung Gesellschaft (MDG) in 1994/95 to determine whether there are any ways in which diocesan newspapers can curtail declining circulation or perhaps even win back lost ground. To this end, a comparative situational analysis was completed for 18 German diocesan newspapers from various perspectives. Aside from subscribers and persons who had cancelled their subscriptions, other persons interviewed were bishops (in their capacity as editors of the publications), publishers, editors-in-chief, sales managers, as well as priests and representatives of Catholic lay organizations as potential multipliers.

The findings of the study support the thesis that the church newspapers have not simply fallen victim to external trends, such as weakened ties to the church; rather, there are also a number of weaknesses of their own making. At the same time, the findings clearly show that the church newspapers are founded on a serviceable core concept: the newspapers continue to represent an important means of communication for the 1.2 million subscribers, or, respectively, for the 4.9 million Catholics who belong to the broadest readership group, and as a rule, these newspapers are not simply read in order to demonstrate support for the church, but are instead viewed as an interesting source of reading material. Beyond that, the core concept appeals to a substantial group of persons who would potentially be interested in the themes covered, i.e. about one third of all Catholics. 
In view of declining church income from tax revenues and a growing need for subsidies, the church newspapers must cooperate with each other. Subscribers to cooperative newspapers are just as satisfied with the journalistic quality of their church newspapers, with the reporting on the diocese and parish, as are subscribers to individually published diocesan newspapers.

\section{RÉSUMÉ: Quelles chances pour les journaux d'évêchés}

La diminution constante du tirage des journaux d'évêchés et le vieilissement du cercle des lecteurs sont des symptômes significatifs d'une crise existentielle de ce genre de média. Chargé par la Société de service des médias (MDG), l'institut de science de l'opinion Allensbach a donc examiné pendant les années 1994/95 s'il existait des chances pour les journaux d'évêchés de freiner cette baisse de tirages au même de regagner le terrain perdu. Pour cela, il a été effectué une analyse comparative de la situation auprès de 18 journaux d'évêchés, à partir de différentes perspectives. A côté des abonnés, des personnes qui ont résilié leur abonnement de journaux ecclésiastiques, on a aussi posé des questions aux évêques en tant qu'administrateur, éditeur, rédacteur en chef et chef de vente ainsi qu'aux prêtres et représentants d'organes catholiques séculiers en tant que multiplicateurs potentiels. Les résultats de ce sondage appuient la thèse selon laquelle les journaux ecclésiastiques ne sont pas seulement victimes d'un affaiblissement d'engagements religieux, mais qu'ils ont aussi leurs propres faiblesses "internes". En même temps, on remarque bien que la conception centrale des journaux religieux offre une substance valable: lls représentent toujours un important moyen de communication pour 1,2 million d'abonnés et 4,9 millions de catholiques. De plus, la conception centrale intéresse au niveau psychologique un potentiel important de personnes, soit environ un tiers de tous les catholiques.

Devant la baisse de perception des impôts ecclésiastiques et le besoin grandissant de subventions, les journaux ecclésiastiques doivent être prêts à plus de coopérations. Les abonnés de journaux faits en coopération ne sont pas moins satisfaits de la capacité de publication de leur journal religieux et des articles sur leur diocèse et leur paroisse que les abonnés de journaux d'évêchés provenant de maisons d'édition isolées.

\section{RESUMEN: Oportunidades para la prensa diocesana}

La continua disminución de tirada y la alta edad de los lectores son signos claros de una crisis existencial del género. Por encargo de la Medien Dienstleistung Gesellschaft (MDG), el Institut für Demoskopie Allensbach (Instituto de demoscopía de Allensbach) ha analizado en 1994/95 si la prensa diocesana tiene posibilidades de detener la disminución de las tiradas o de recuperar terreno perdido. Para ello realizó un análisis comparativo, pertiendo de distintas perspectivas, de 18 periódicos diocesanos alemanes. Fueron entrevistados subscriptores y ex-subscriptores de estos periódicos, obispos en su función de editores, jefes de redacción y jefes de distribución, así como sacerdotes y representantes de los gremios laicos en su función de potenciales multiplicadores. Los resultados de esa investigación apoyan la tesis de que los periódicos diocesanos no son sólo víctimas de la creciente desligamiento de los fieles de la iglesia, sino que también tienen debilidades que les son propias "de la casa". Al mismo tiempo queda claro que el concepto fundamental de los periódicos posee una base con futuro: constituyen para 1.2 millones de subscriptores o para 4.9 millones de católicos un importante medio de comunicación. Además, la idea básica corresponde a un gran interés potencial psicológico de casi un tercio de todos los católicos. 
En vista de la disminución de los ingresos por el „impuesto de la iglesia“ y de la creciente necesidad de subvenciones, los periódicos diocesanos tienen que procurar el aumento de las cooperaciones. Los subscriptores de periódicos en cooperación no están menos satisfechos con el rendimiento en publicidad de su periódico eclesial y con los reportajes sobre las diócesis y las parroquias que los subscriptores de los periódicos diocesanos. 